\title{
ESTIMATION OF DYNAMIC LOAD DEMAND ON A GROUND SUPPORT SCHEME DUE TO A LARGE STRUCTURALLY CONTROLLED VIOLENT FAILURE - A CASE STUDY
}

\author{
Christopher Drover, Ernesto Villaescusa \\ Western Australian School of Mines, CRC Mining, Curtin University \\ Email: christopher.drover@crcmining.com.au, e.villaescusa@curtin.edu.au
}

\section{Abstract}

In the future a larger proportion of underground mines will operate in deep, high stress environments where excavations may be exposed to very high loading demands. This case study has examined a violent structurally controlled failure occurring in a deep hardrock underground mine at a depth of 1055 metres below surface. On the basis of the damage observations the back analysis of this event concludes that the surface support system was ejected from the wall of the excavation with an initial velocity of $10.7 \mathrm{~m} / \mathrm{s}$. Estimates of the mechanical demand imparted to the ground support scheme during failure were also calculated. These estimates carry several assumptions in order to simplify complex uncertainties concerning the loading mass of rock and transfer of kinetic energy between the rock and ground support. However, the demand may be conservatively assumed to be at least $150 \mathrm{~kJ} / \mathrm{m}^{2}$. These results may reflect future mining conditions at great depth.

Keywords - energy demand, violent failure, ejection velocity

\section{Introduction}

One of the fundamental challenges in the design of underground mining excavations constructed at great depth is the accurate forecasting of the dynamic loading demands which are experienced by the installed ground support schemes. A common design methodology is to consider the energy dissipation capacity of a chosen ground support scheme relative to the kinetic energy demand of a mass of failing rock that the scheme may be required to retain. This method necessitates an estimation of both the mass and velocity of rock which may be mobilised during some future rock mass failure event. Both variables are subject to considerable uncertainty at the design stage due to the mechanical complexity of the failure process, considering rock strength, structural characteristics, mining induced stress conditions and excavation geometry.

Back analysis of real case studies of violent excavation failure provides insights into both ejection velocity and the depth of rock mass failure. This information may then be used to calculate energy demand on the installed ground support. The objective of this case study is to quantify the energy demand during a specific incidence of violent excavation failure. This analysis serves as an example of the dynamic demands that may be encountered when mining at great depth, particularly when failure mechanisms involve large scale, structurally controlled loading mechanisms.

This case study occurs within the context of an underground hardrock mine operating at great depth. The mine is a mass caving operation subject to conditions of high rock stress. The cave is mature, having been initiated at shallow depth beneath a pre-existing open pit, with subsidence continuous to surface. The cave pipe extends from surface to the deepest production horizons located at a depth of 1100 metres. Development workings in advance of the cave front extend to a depth of 1250 metres below surface. 
At this operation the permanent infrastructure such as material haulage drives, shaft and main decline are all located in the west domain of the orebody within a high strength rock mass (Figure 1). Production level access development is also located in the west domain. The orebody is extracted via transverse caving and is approximately 150 metres wide along strike and 200 metres wide across strike. A narrow mineralised limb extends some 90 metres north of the primary cave zone and this is also caved (Figure 1). The full width of the cave zone is therefore approximately 240 metres parallel to strike. This dimension is sub-perpendicular to the orientation of the pre-mining major principal stress and therefore the process of caving the orebody induces considerable alteration of the stress field.

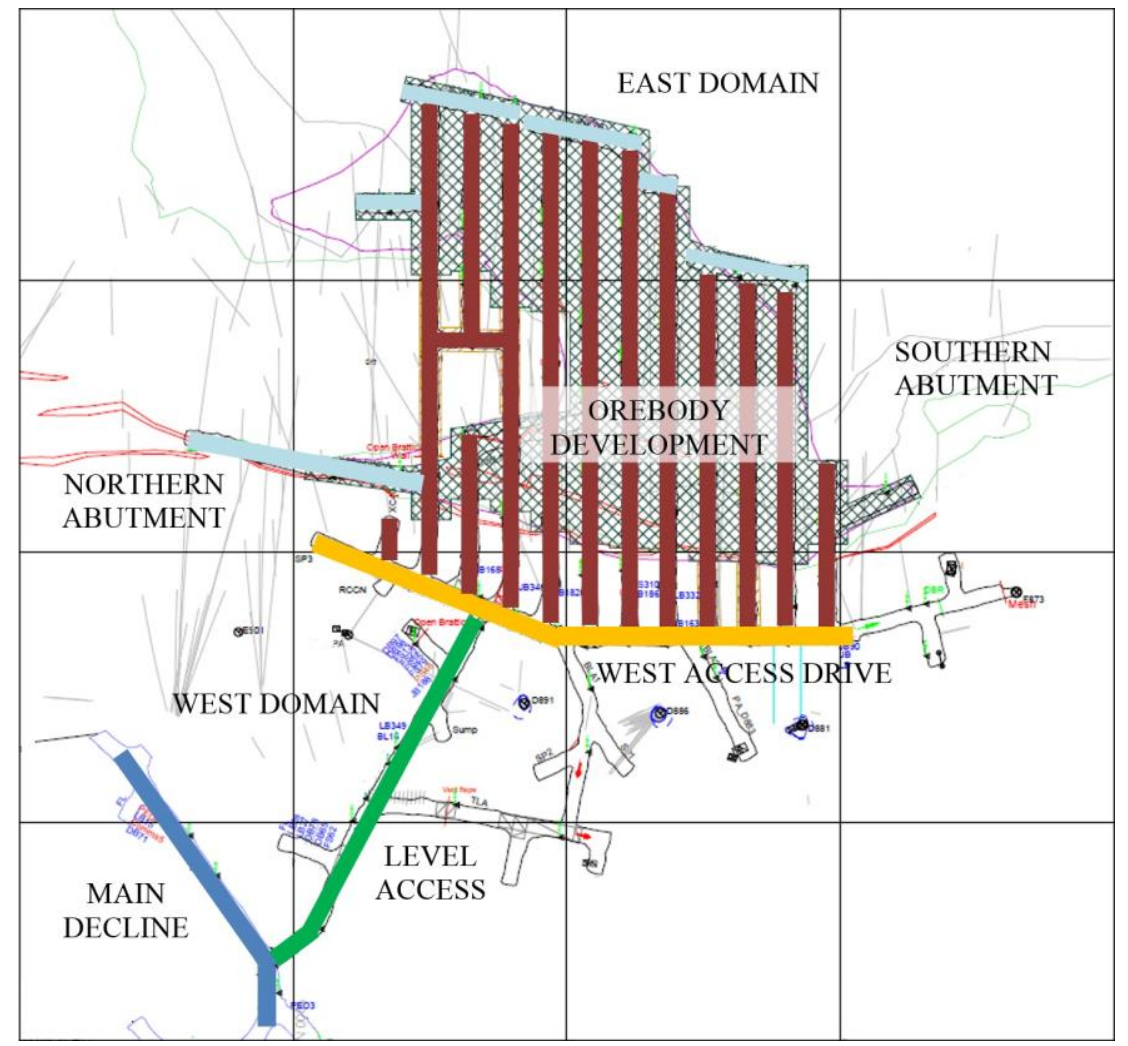

Figure 1 - Plan view of mining infrastructure (grid 100m).

\section{Geology, Structure, Stress and Seismicity}

The geotechnical performance of the mine has been governed by three critical factors. The first is the spatial arrangement of rock types and their material properties, inclusive of intact rock properties, as well as those of discontinuity infill materials between adjacent blocks. The rock types present within this mine range from very stiff and strong metasedimentary rocks to relatively ductile ultramafic types. The range of infill material is similarly diverse, ranging from well healed igneous intrusive material such as pegmatite through to low friction tochilinite. Generally the weaker rock types host the weaker infill materials and vice versa. The diversity of rock types yields a variety of mechanical reactions when the rock is subjected to an applied loading and these characteristics demand a similarly diverse range of reinforcement and support designs. 
The second factor governing geotechnical performance is the structural geology of the mine. Specifically, the location, orientation, spacing and strength properties of primary features such as mine scale fault structures, as well as secondary features such as precinct scale joint sets and tunnel scale minor joints and foliation. These features are a product of the tectonic setting and have evolved over time. The third and final factor is the in-situ stress regime. That is, the magnitude and orientation of the principal stresses and their variation in response to the changing shape of mining voids. The mining operations occur in a deep, high stress environment with large scale ore extraction. This creates conditions where the mining induced stresses are often concentrated and constantly adjusting to the mining geometry. The combination of these three critical factors places significant demands on the ground support schemes.

\subsection{Geology of the Mine}

The mine may be broadly subdivided into east and west geological domains. The east domain consists of a mineralised ultramafic sequence where the dominant rock mass failure behaviour is a non-violent, time dependent convergence. The waste rock of the west domain is a felsic type prone to sudden violent failure due to its inherent material properties of strength and stiffness. This rock type was host to a severe case of excavation damage caused by a violent rock mass failure and so forms the focus of this discussion. West domain felsic rock types include metabasalts, metasedimentary schists, metavolcaniclastic schists and plagioclase-quartz porphyries. Although these rock types fall under the felsic categorisation, the material properties of the types are sufficiently diverse to cause varying mechanical reactions between the units. The boundaries of rock types relevant to the mining level where violent failure occurred are shown in Figure 2.

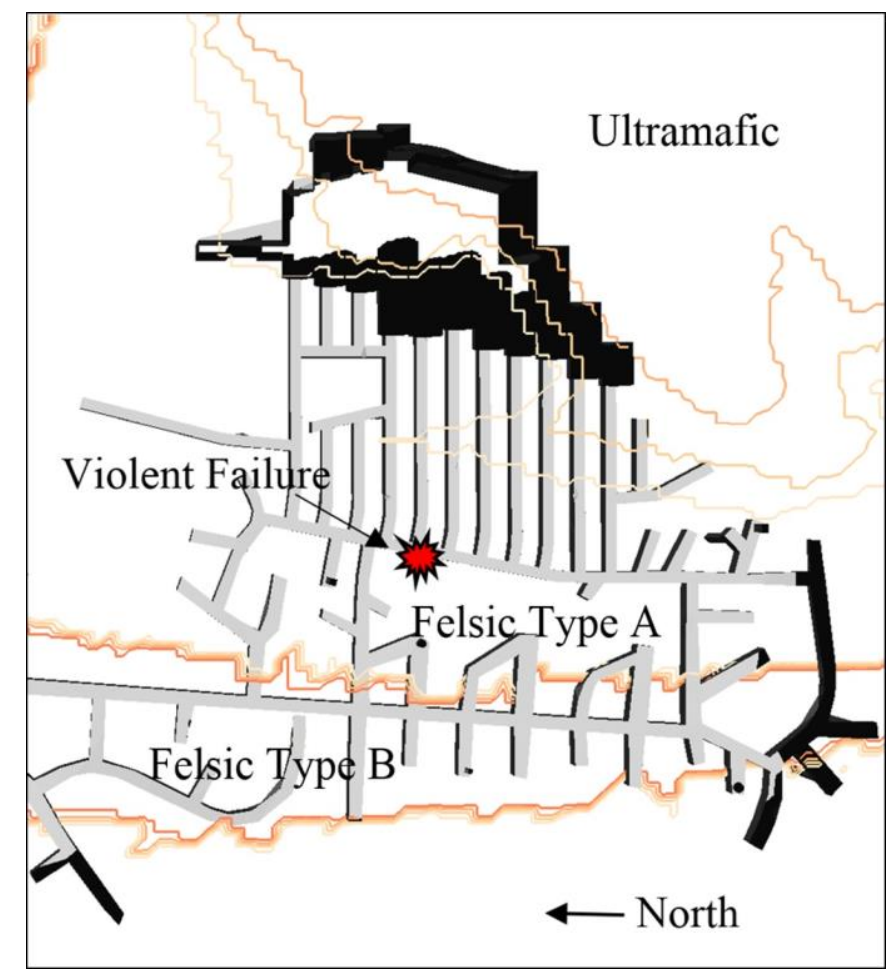

Figure 2 - Rock type boundaries where failure occurred. 


\subsection{Rock Properties}

This failure case study occurred in the central west domain of the orebody in the west access drive. The variability in rock strength surrounding the failure location is shown in Figure 3. The failure was located in a felsic rock mass with a UCS ranging from 100-125MPa. Figure 4 presents typical diamond drill core of felsic material. Note the contrast between intact core samples and a discrete fracture zone at $59.2 \mathrm{~m}$ representing a local geological structure. Such structures are common sources of seismic activity in the west domain of the mine. Material properties of the felsic rock types have been compiled via laboratory strength testing of core samples. A summary of rock properties relevant to the failure site are presented in Table 1.

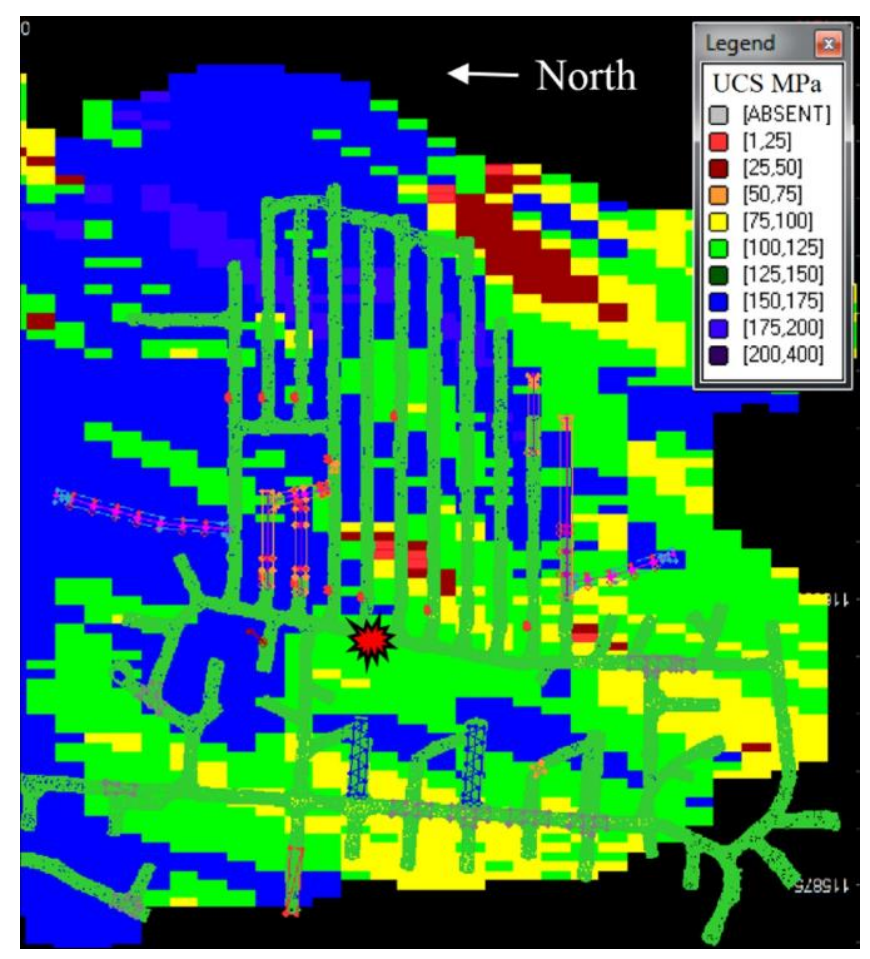

Figure 3 - UCS (MPa) block model for the mining level where violent failure occurred.

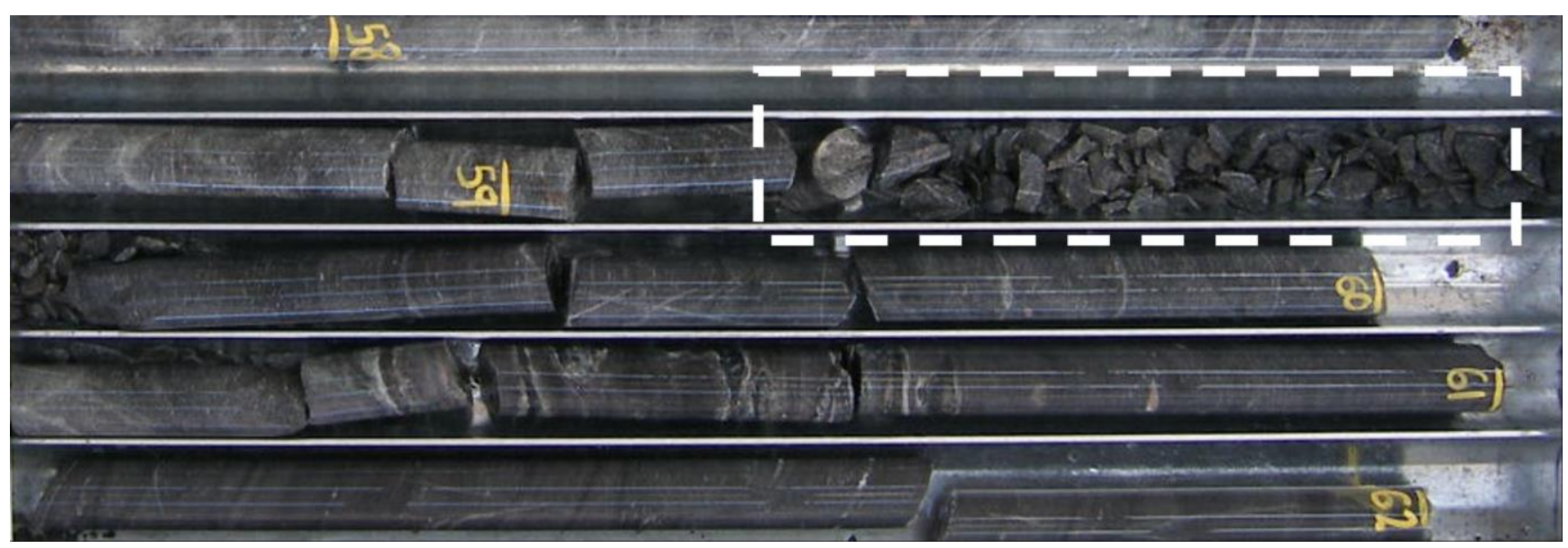

Figure 4 - Felsic drill core from the west domain showing intact rock and the effect of local geological structure. 
Table 1 - Mechanical properties of the Felsic host rock relevant to the site of excavation failure.

\begin{tabular}{|c|c|c|}
\hline $\begin{array}{c}\text { Unit Weight } \\
\left(\mathrm{kN} / \mathrm{m}^{3}\right)\end{array}$ & $\begin{array}{c}\text { UCS } \\
(\mathrm{MPa})\end{array}$ & $\begin{array}{c}\text { UTS } \\
(\mathrm{MPa})\end{array}$ \\
\hline 27 & $100-125$ & 14 \\
\hline $\begin{array}{c}\text { Modulus of } \\
\text { Elasticity } \\
(\mathrm{GPa})\end{array}$ & $\begin{array}{c}\text { Poisson's } \\
\text { Ratio }\end{array}$ & $\begin{array}{c}\text { Modulus } \\
\text { of Rigidity } \\
(\mathrm{GPa})\end{array}$ \\
\hline 56 & 0.23 & 23 \\
\hline
\end{tabular}

\subsection{Structural Geology}

The intricate structural characteristics of the mining environment are shaped by the regional tectonic setting (Windsor, 2008). The complexity of the system of rock structures contributes to the potential for sudden violent rock mass failure. Mining induced seismic events at the mine often exhibit high S-wave to P-wave ratios, indicating that seismic activity is regularly caused by fault-slip source mechanisms. The recorded incidences of fault rupture seismicity in the west domain indicate that many structures have been mobilised due to the influence of the mining induced stress conditions. However, not all of the structurally controlled rock mass failures have been observed to cause damage to excavations.

The susceptibility to rupture of rock structures depends on a variety of factors, such as the magnitude and orientation of the applied loads relative to the structure, as well as joint surface characteristics such as topography, roughness, wall strength, filling and the presence of groundwater (Brown, 1981). The variability in these factors across the various discontinuities dictates that some structures present weaker and more susceptible to rupture than others. It is these weaker structures which preferentially generate rock mass damage.

Over the course of several years a number of significant geological structures have been identified within the mining precinct as having an increased potential to generate sudden violent events. This conclusion is drawn on the basis of recorded fault-slip seismic activity coincident with these structures and associated ground support damage where these structures intersect excavations. A map of these structures is shown below in Figure 5.

Fault Set \#1 exhibits repetitive rupture behaviour with numerous large events recorded along these structures in the past. This set has a strike orientation in the north eastern direction and sub-vertical dip to the northwest. The faults persist across both the felsic and ultramafic domains. However, the potential for sudden violent failure has only been observed in felsic material such as that in the west domain and felsic contact folding in the northern abutment of the orebody.

Fault Set \#2 consists of a group of east-west striking discontinuities with a vertical dip. Structures within this set are considered to be brittle faults with smooth, undulating surfaces and they are also potentially groundwater conduits. Several large seismic events $\geq 2.0 \mathrm{M}_{\mathrm{L}}$ have been recorded coincident with these structures in the past, indicating a propensity for repetitive fault-slip rupture over time. 
The major structure relevant to this failure case study strikes east-west across the full width of the mining precinct. This steeply north-dipping feature is referred to as Major Structure \#1 in Figure 5. Major Structure \#1 bisects the cave and adjacent mine development through the central west domain and is a known source of seismic activity. Following a mine scale episode of instability, this structure was central to the majority of ground support damage on this particular level of the mine. The severity of the damage indicates that this structure is capable of generating extremely high dynamic loading demands.

In addition to joint sets and major faults, the felsic west domain is heavily structured with smaller scale structural features. Steeply dipping, tightly spaced foliations striking sub-parallel with the orebody-west domain contact are a common feature of this rock type. Joint set characteristics in the felsic rock mass tend to be undulating and either smooth or rough. Infill materials are typically well healed intrusive minerals such as quartz or pegmatite. Therefore, structures in felsic tend to be high strength, brittle and prone to sudden violent failure.

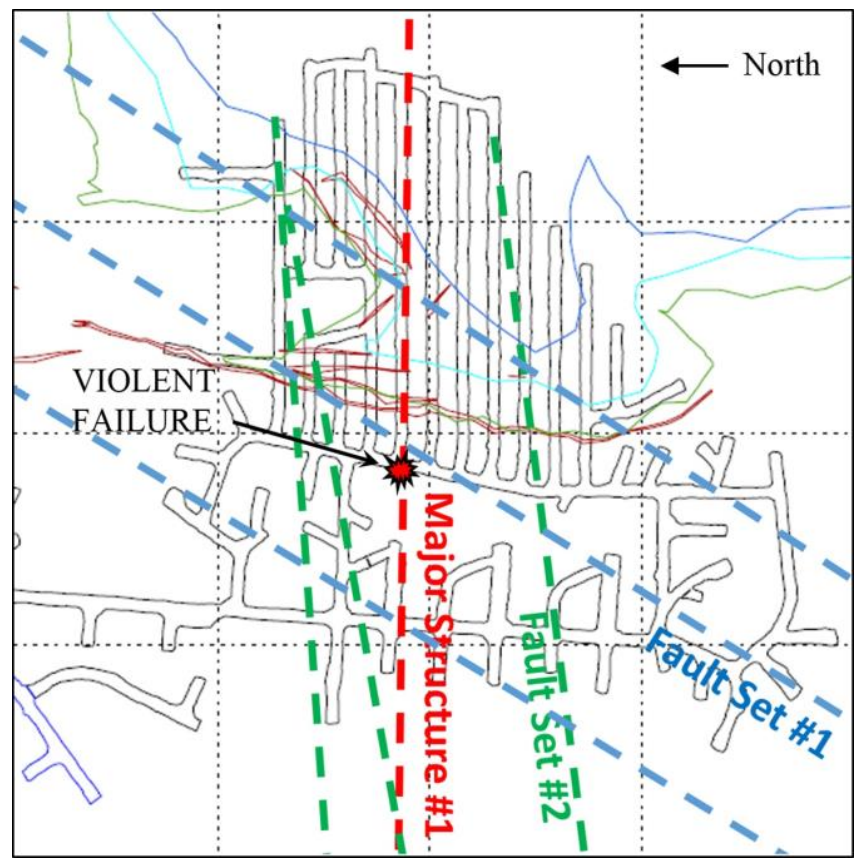

Figure 5 - Plan view sketch of mine development, basic geology and significant seismically active structures with respect to the location of violent failure.

\subsection{Induced Stress and Seismicity}

At the mine scale, conditions of induced stress are largely determined by the shape, dimensions and extraction schedule of the cave. Mining activity forces the east-southeast oriented pre-mining major principal stress to deviate around the cave, relaxing in the central west and east domains to approximately $40 \mathrm{MPa}$. Given the 100-125MPa compressive strength of the rock coinciding with the location of violent failure, the ratio of rock strength $\left(\sigma_{c}\right)$ to the induced stress $\left(\sigma_{\max }\right)$ in the general vicinity of the excavation failure may be estimated to be in the range of 2.5 to 3.1. This ratio may be less than 2.5 on the excavation boundary where failure occurred. In the northern and southern abutments and abutment beneath the cave the induced stress regularly approaches $100 \mathrm{MPa}$, and possibly higher where localised stress concentrations occur around excavations due to the effect of geometry. 
This process is illustrated by non-linear finite element modelling shown in Figure 6 as a series of long section views of the lower mine workings. These figures demonstrate how the process of stress redistribution around the cave controls the loading conditions to which development excavations are subjected. These zones of high rock mass loading generate seismicity and may be offset by several tens of metres from the cave due to stress shadowing effects and local zones of yielded ground around the perimeter of the cave.

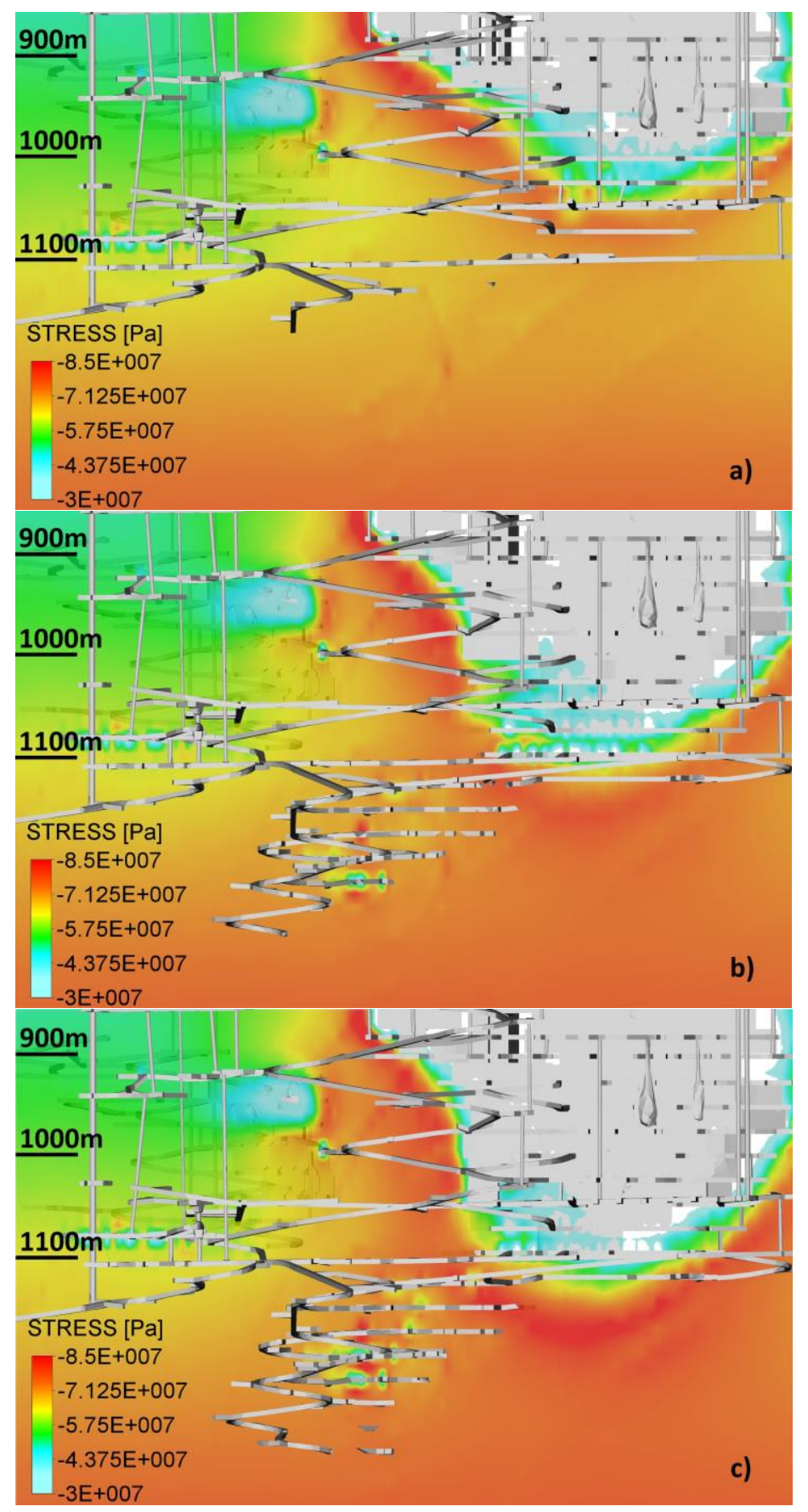

Figure 6 - Long sections of modelled major principal stress showing increasing stress concentrations in the cave abutments for three cave extraction steps. 
The location of the high stress seismogenic zone (Duplancic, 2001) shifts with time, depending on the position of the cave front. Prior to the cave reaching $1100 \mathrm{~m}$ below surface (Figure 6a) this high stress zone was consistently around 50 metres below the cave. As the cave front was excavated deeper (Figure 6b) the zone of high stress also advanced deeper, thus forming a prominent seismogenic precinct around the lower development workings. As the cave reached 1100 metres below surface (Figure 6c) an inflection in the orebody caused very high stress concentration beneath the cave where the rock type changes from ultramafic to felsic. The seismogenic zone no longer advanced deeper as the cave was enlarged. Instead, it became stationary as the felsic rock beneath the cave assumed loads more quickly than could be dissipated gradually by low energy failure mechanisms.

Further detail on the stress concentration around the cave is shown below in Figure 7. This figure is a horizontal section view of stress modelling results taken at a depth of 1055 metres below surface and coincides with the geometry of the cave at the time of violent failure. These results illustrate how the strike width of the cave has a significant influence on the location and magnitude of the concentrated stresses. Note that this figure illustrates an established production level approximately 45 metres above the orebody inflection and therefore does not show the lower abutment stress conditions. The location of the most severe excavation damage was in an area predicted to be subject to relatively low mining induced stress of 40MPa. This may be explained as a structurally controlled mechanism of failure, rather than a stress driven mechanism, as explained later.

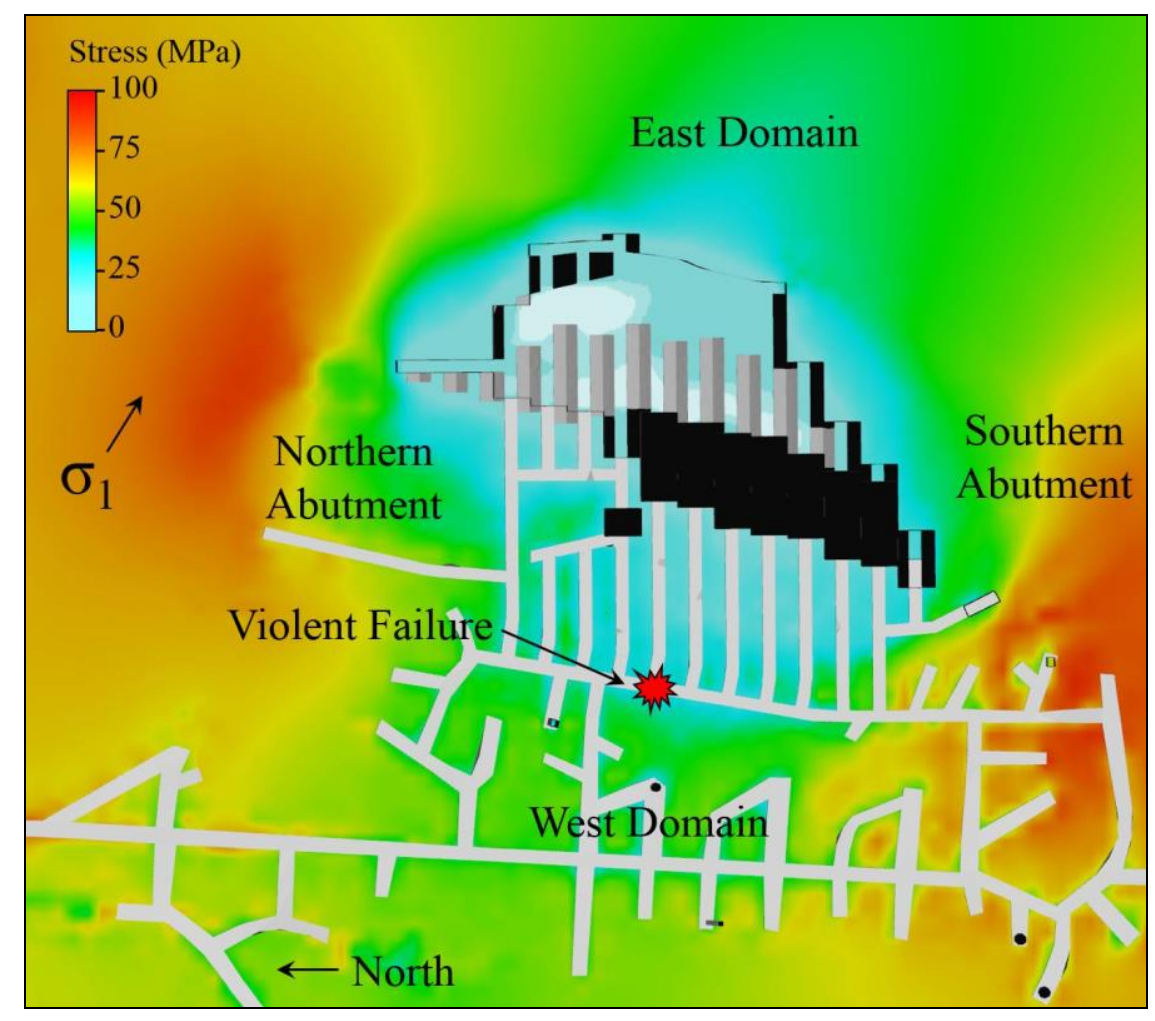

Figure 7 - Plan view of modelled mining induced stress around the cave at the time of violent failure, taken at a depth of $1055 \mathrm{~m}$. 
The consequence of these heavily concentrated stress conditions is elevated seismic activity. Seismicity in the northern abutment of the cave over a period of 48 hours following a mine scale instability event is illustrated in Figure 8. The shape and position of the seismogenic zone caused by this failure coincides with areas of very high stress concentrations predicted by the non-linear numerical modelling. As the cave approached the structural inflection of the orebody, 1100 metres below surface, the stresses beneath the cave began concentrating above the critical threshold of rock strength capable of sustaining these loads without large scale failure. This lead to an increase in the frequency and magnitude of large events as the cave was extracted deeper towards the inflection.

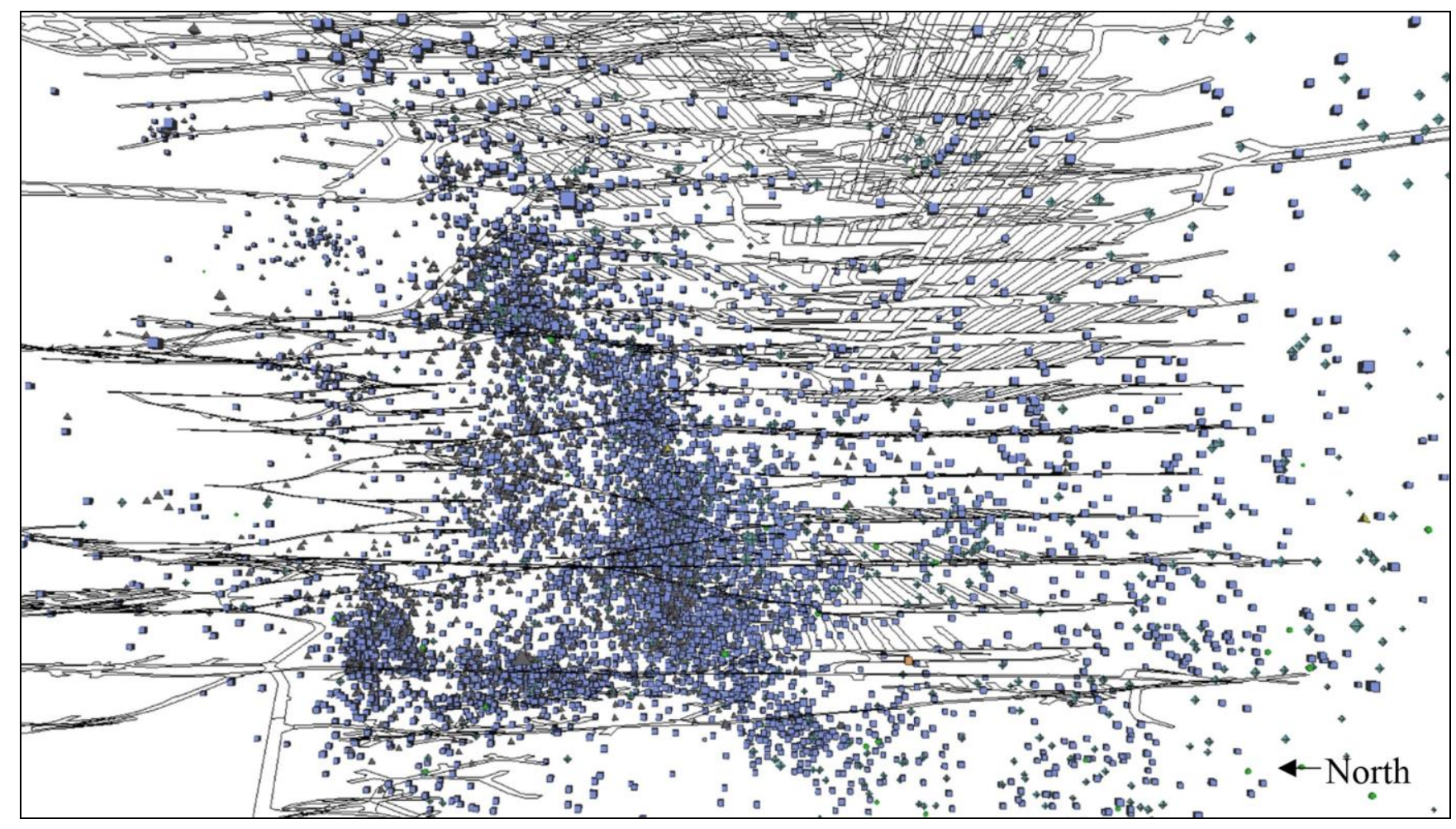

Figure 8 - Seismogenic zone in the northern cave abutment following a large dynamic failure.

A total of six seismic events exceeding $+2.0 \mathrm{M}_{\mathrm{L}}$ were recorded immediately adjacent to the cave during the two years preceding this major instability event. Despite the increasing incidence of large events, none resulted in widespread ground support failure. This fact can be explained by the notion that the most energetic rock mass failure mechanisms did not intersect the excavations and therefore did not impart loads upon the reinforcement and support which would cause severe damage.

The mining induced conditions of stress described in this case study suggest a vulnerability inherent to all mass caving mines operating at great depth and high stress. The abutments of such operations inevitably become heavily loaded due to the stress concentration effects of the cave geometry. Excavations and the installed ground support schemes within these zones may therefore become exposed to extremely high rock mass demands which may be sufficient to cause sudden violent failures. 


\section{Ground Support Schemes}

The excavation shape and installed ground support schemes relevant to this case study are shown in Figure 9 and Figure 11. These figures illustrate a section view of the entire ground support scheme, the plan view of reinforcement and mesh surface support installed in the roof of the excavation and a long section view of the wall reinforcement and mesh arrangement up to the shoulder height. The scheme depicted in Figure 9 is used in west domain development where medium energy demands (Villaescusa, et al., 2014) of 5-15kJ/m are expected, such as level accesses, materials handling drifts and the main decline. The scheme consists of the following components, as illustrated:

Surface Support

- Steel fibre-reinforced shotcrete ( $75 \mathrm{~mm}$ roof, $50 \mathrm{~mm}$ walls, $25 \mathrm{~mm}$ lower wall overspray),

- Mild steel weld mesh, $5.6 \mathrm{~mm}$ gauge, $100 \mathrm{~mm}$ aperture, $3.0 \mathrm{~m} / 3.6 \mathrm{~m}$ x $2.4 \mathrm{~m}$ sheets. Reinforcement

- $2.4 \mathrm{~m}$ long R27 Secura bolt, continuous mechanical couple, resin encapsulated,

- $2.4 \mathrm{~m}$ long SS46 Split Set Stabiliser, continuous frictional couple.

Fibrecrete is one of two surface support components used in dynamic loading conditions. It is the first component to be installed in the ground support cycle. The intent of fibrecrete is to provide consolidation of small loose blocks around the excavation boundary, ideally penetrating small perimeter fractures to then provide limited confinement to the rock mass between adjacent reinforcement elements. Fibrecrete is initially applied at $50 \mathrm{~mm}$ thickness to walls and $75 \mathrm{~mm}$ thickness to the roof of the excavation. This is the minimum desired thickness. In-cycle quality control procedures confirm that this minimum thickness is reliably achieved.

Sheets of weld mesh are subsequently arranged using 1.5 metre long split set stabilisers such that the mesh fully covers the final excavation surface, excluding the floor. The primary function of the mesh is to retain small destabilised blocks of rock or fibrecrete which may form between the span of adjacent reinforcement elements. Mesh also provides connectivity and load transfer between neighbouring reinforcement elements in the event of mesh loading or isolated reinforcement failures.

Rock mass damage may accumulate at the excavation perimeter due to blast damage, stress induced fracturing or unravelling of tightly spaced natural discontinuities. The retention capacity of the mesh in these scenarios is transferred to the reinforcement elements as the mesh is not usually encapsulated in fibrecrete. Typically, the weld mesh is only encapsulated in fibrecrete at the lower walls, where a $25 \mathrm{~mm}$ overspray is applied for protection against mobile equipment damage. Full profile encapsulation of the mesh in fibrecrete is generally only applied in materials handling drifts such as stockpiles.

Reinforcement elements are installed and the mesh secured as the final phase of the ground support cycle. At the failure site the installed reinforcement includes $2.4 \mathrm{~m}$ long R27 Secura bolts as the primary element for the upper walls and roof. All reinforcement elements were designed to be installed as continuous mechanically coupled elements using quick set chemical resin as the bonding agent. Pattern reinforcement was installed on a 1.4 metre row by 1.1 metre in-row spacing. SS46 Split Set friction stabilisers were installed in the lower walls on a $1.1 \mathrm{~m}$ diamond pattern. 


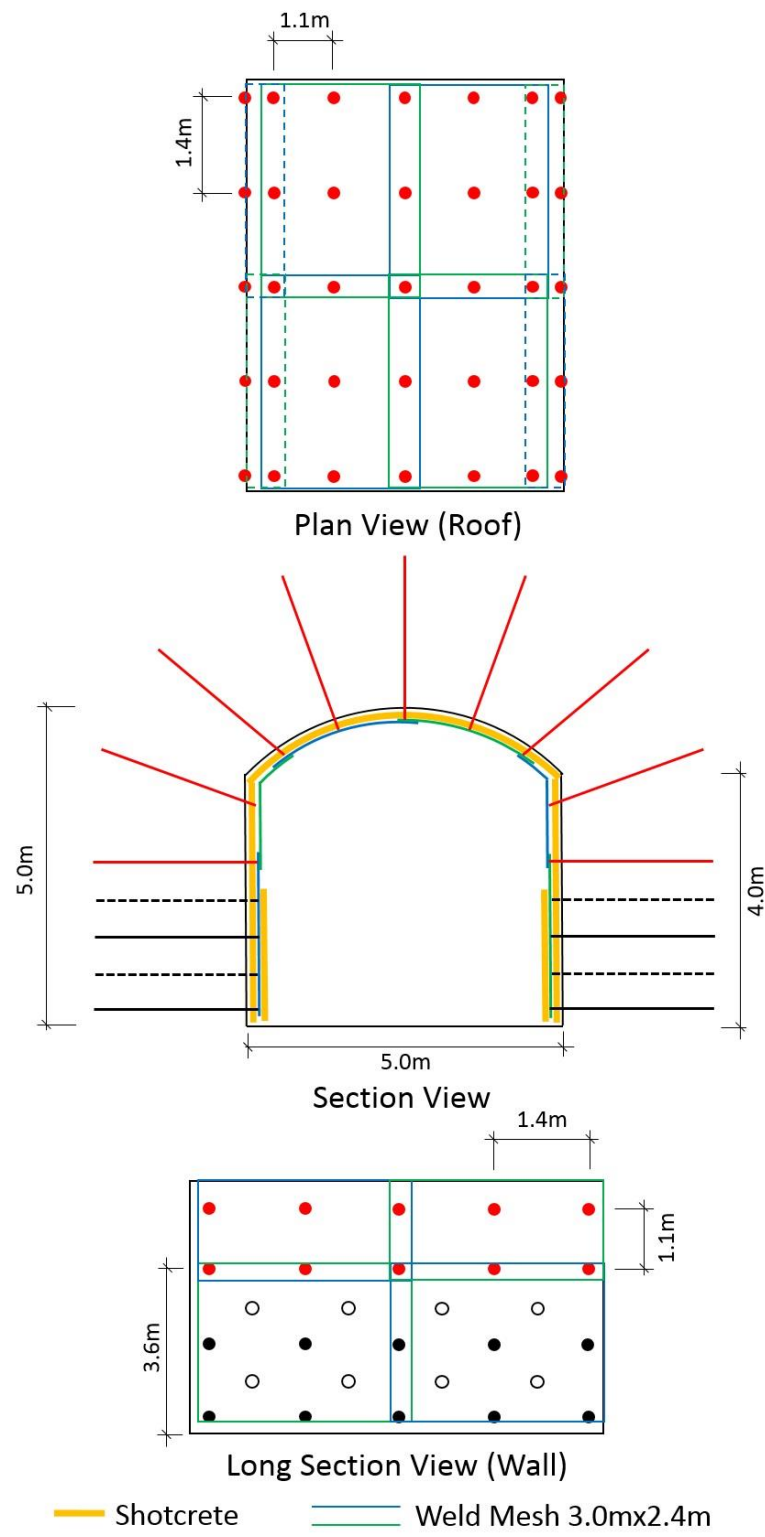

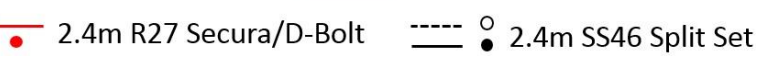

Figure 9 - Excavation shape and ground support scheme for conditions of medium energy demand.

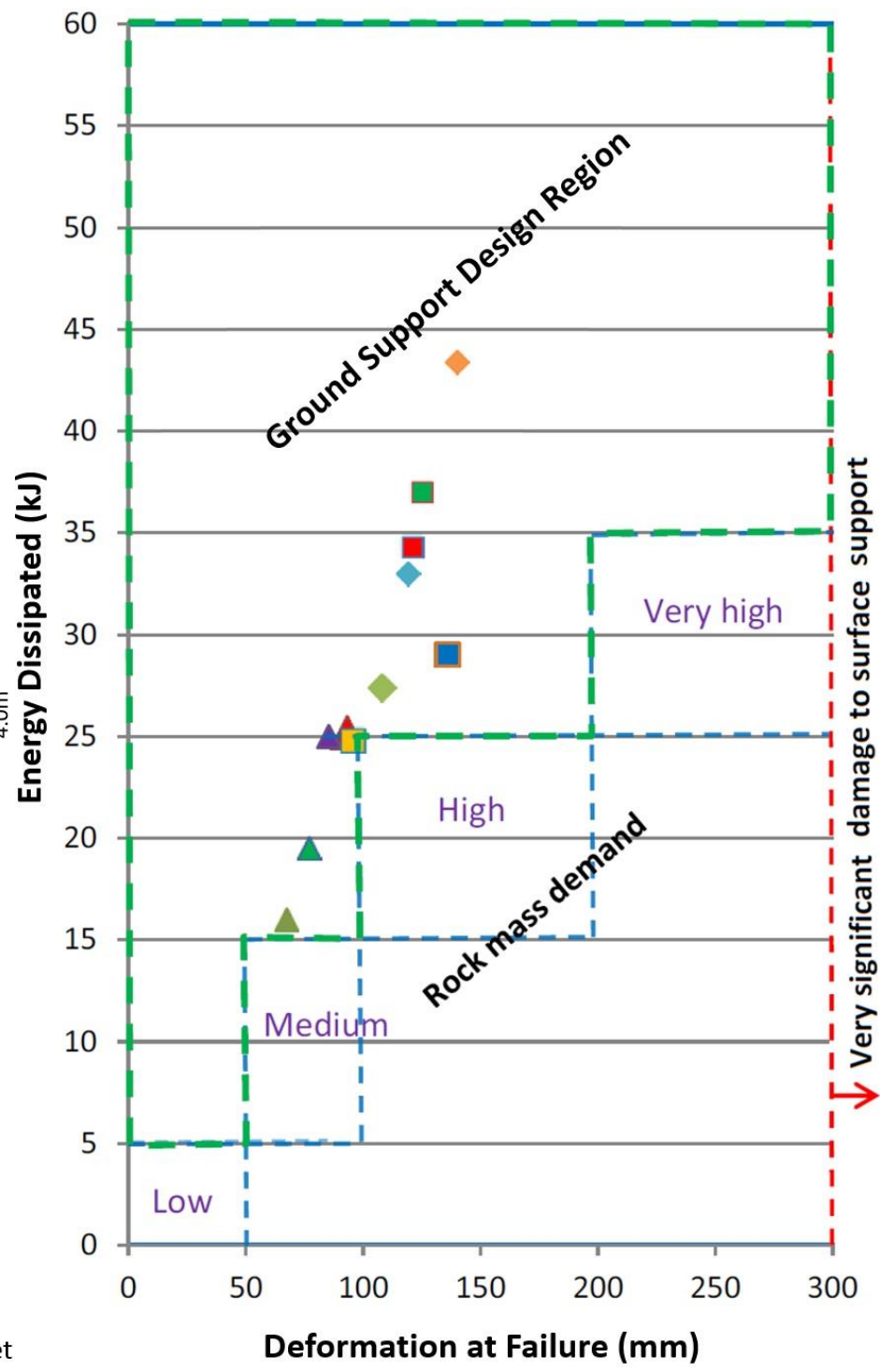

Figure 10 - Energy dissipated versus deformation at failure for combined schemes of rock bolts and mesh tested at WASM.

2.4m 550MPa 20mm threaded bar, chain link mesh

$\triangle 2.4 \mathrm{~m}$ 550MPa 20mm threaded bar, chain link mesh

A2.4m 550MPa 20mm threaded bar, 5.6mm weld mesh.

А2.4m 550MPa 20mm threaded bar, $5.6 \mathrm{~mm}$ weld mesh.

$2.4 \mathrm{~m} 550 \mathrm{MPa} 20 \mathrm{~mm}$ threaded bar, Im centrally decoupled, $5.6 \mathrm{~mm}$ weld mesh

$\square 2.4 \mathrm{~m} 550 \mathrm{MPa}$ 20mm threaded bar, 1m centrally decoupled, chain link mesh

2.4m 550MPa $20 \mathrm{~mm}$ threaded bar, Im centrally decoupled, chain link mesh

2.4m 550MPa $20 \mathrm{~mm}$ threaded bar, Im centrally decoupled, $5.6 \mathrm{~mm}$ weld mesh

$\checkmark 3 \mathrm{~m}$ 550MPa $20 \mathrm{~mm}$ DSI Posimix, $1.4 \mathrm{~m}$ decoupled, 4mm chain link mesh

$3 \mathrm{~m}$ 550MPa $20 \mathrm{~mm}$ DSI Posimix, 1.4m decoupled, chain link mesh

3m 550MPa 20mm DSI Posimix, 1.4m decoupled, chain link mesh 
The energy dissipation capacity of the ground support scheme installed in this failure case study can be estimated by comparing the design with the results of combined bolt and mesh schemes tested at the WA School of Mines (Figure 10). The test schemes consisting of $20 \mathrm{~mm}$ diameter, cement grouted, continuously mechanically coupled threaded bar and 5.6mm gauge weld mesh have been referenced as the most relevant for energy dissipation comparison. This is considered to be a conservative comparison due to the higher expected dynamic capacity of the $27 \mathrm{~mm}$ diameter Secura bar, which was installed at the failure site. An adjustment of $+2 \mathrm{~kJ} / \mathrm{m}^{2}$ is made to the test results in order to account for the additional capacity provided by fibre-reinforced shotcrete, which was not included in these combined test schemes.

\section{Upper Walls / Roof}

Fibrecrete $\left(2 \mathrm{~kJ} / \mathrm{m}^{2}\right)+$ Mesh $/$ Secura Bolt $\left(16 \mathrm{~kJ} / \mathrm{m}^{2}\right)=18 \mathrm{~kJ} / \mathrm{m}^{2}$ at $\leq 100 \mathrm{~mm}$ displacement.

Combined Scheme testing of SS46 Split Sets and mesh is not available. Therefore, the energy dissipation capacity of the lower wall ground support scheme has been estimated as the sum of the capacity of individually tested components. Reinforcement capacity test data is sourced from Villaescusa, et al., 2014.

\section{Lower Walls}

Fibrecrete $\left(2 \mathrm{~kJ} / \mathrm{m}^{2}\right)+\operatorname{Mesh}\left(2.5 \mathrm{~kJ} / \mathrm{m}^{2}\right)+\operatorname{SS} 46 \operatorname{Split} \operatorname{Set}\left(6 \mathrm{~kJ} / \mathrm{m}^{2}\right)=10.5 \mathrm{~kJ} / \mathrm{m}^{2}$ at $\leq 100 \mathrm{~mm}$ displacement.

In addition to the standard scheme, an upgraded roof support scheme was installed due to high to very high rock mass demand expectations of $15-35 \mathrm{~kJ} / \mathrm{m}^{2}$. This upgraded scheme is generally installed within the zone of high stress concentration in the west domain and wherever development is known to intersect any major geological structure which exhibits potential to generate dynamic loading demands within the aforementioned demand range. The scheme is illustrated in Figure 11 and consists of a $6.0 \mathrm{~m}$ long by $0.3 \mathrm{~m}$ wide heavy gauge mild steel mesh strap installed in a transverse orientation across the roof of the excavation. These straps were secured at 1.5 metre intervals using 8 metre long, twin plain strand cable bolts. Spacing between straps is 1.4 metres.

The total energy dissipation capacity of this upgraded ground support scheme is also calculated based upon the available combined scheme and individual component capacities defined by testing (Villaescusa, et al., 2014). Energy dissipation of the cable reinforcement reflects capacity provided per unit area $\left(\mathrm{m}^{2}\right)$, taking into account the installed spacing of $1.5 \mathrm{~m} \mathrm{x} 1.4 \mathrm{~m}$ and number of strands per borehole.

\section{Roof:}

Fibrecrete $\left(2 \mathrm{~kJ} / \mathrm{m}^{2}\right)+$ Mesh/Secura Bolts $\left(16 \mathrm{~kJ} / \mathrm{m}^{2}\right)+$ Cables $\left(24 \mathrm{~kJ} / \mathrm{m}^{2}\right)=42 \mathrm{~kJ} / \mathrm{m}^{2}$ at $\leq 150 \mathrm{~mm}$ displacement.

Cable bolts in this scheme are manufactured from high tensile steel and are continuous mechanically coupled to the rock mass with cement grout and tensioned with a face plate. Cables are intended to provide deeper reinforcement where there is potential for significant stress and/or structurally driven depth of rock mass failure and very high energy demand. Past and present examples of sudden violent failure events at this site suggest that depths of failure in the roof of the excavation may exceed $2.5 \mathrm{~m}$. 
This could be pre-existing broken ground or newly developed rock mass disturbance, depending on prevailing stress and rock mass characteristics.

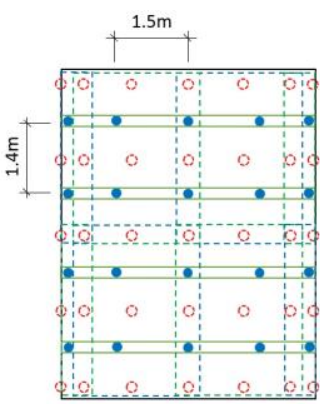

Plan View (Roof)

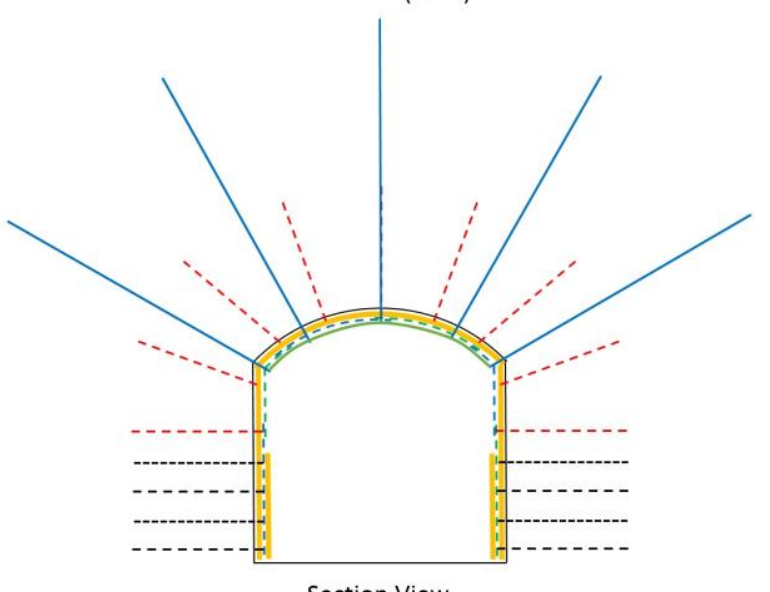

Section View

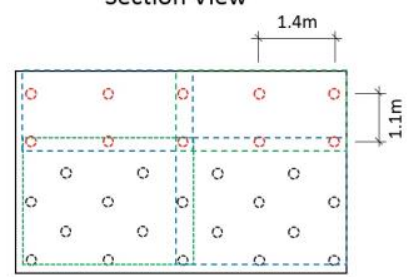

Long Section View (Wall)

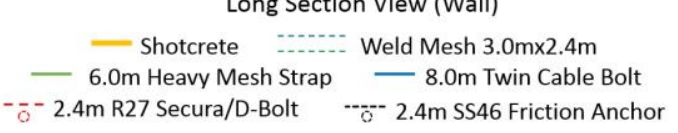

Figure 11 - Second pass upgrade ground support scheme for deep development with $15-35 \mathrm{~kJ} / \mathrm{m}^{2}$ demand. First pass ground support scheme is represented by dashed lines.

\section{Global Failure Mechanism}

The context of this case study is a mine scale episode of rock mass instability which caused extensive damage to the underground excavations. This event was subsequently followed by a period of elevated seismic activity across much of the lower mining precinct. Seismic energy released at the instant of peak instability was calculated to be $2.23 \times 10^{10}$ Joules.

Seismicity recorded at this time is a symptom of the stress driven rock mass damage. It is the portion of energy radiated from the failure that is not already consumed by frictional sliding or creation of new 
fractures (Levkovitch, et al., 2013). As such, it is possible to use the recorded seismicity to assist in an interpretation of the failure source volumes.

Although the radiated seismic energy is not a measurement of the total energy dissipated by the rock mass, or the energy demand applied to the ground support, it is assumed that it is proportional to the dissipated plastic energy of the rock mass during failure (Levkovitch, et al., 2013). Therefore, by calculating the location and energy parameters of the seismic events, the rock mass failure source and spatial distribution of rock mass damage may be inferred. In doing so it is necessary to acknowledge that the failure is not a point source of energy release, rather it is a volume (Eneva, et al., 1998).

For the purpose of the failure source analysis the point dataset of seismic parameters from the population of events shown in Figure 8 have been interpreted using 3D data visualisation software. Zones of inferred rock mass damage shown in Figure 12 are contoured and coloured according to the radiated seismic energy, as per the inset scale. Areas enclosed by higher contours indicate the zones where the rock is considered likely to have yielded and shed load bearing capacity. It is necessary to note that this analysis considers point data of recorded seismicity. As the seismic sources are volumes, the representation of the volume distribution of rock mass damage may be underestimated by this method.

The seismic monitoring system is only capable of recognising one single event in any given second in time. Smaller rock mass failures may not be distinguishable within the recorded seismic waveforms of very large failures if they occur at the same instant. These smaller failures may nonetheless have sufficient energy to cause severe excavation damage. In this case study, during the instant of peak energy release, it is believed that many disparate structurally controlled failure mechanisms occurred throughout a large volume of the mining precinct. This fact must be considered when interpreting the failure source analysis results, as some areas which also suffered rock mass damage may not have been recorded as seismicity.

A sketch of the interpreted global mechanism of failure is shown below in Figure 12. The sketch is centred on the mining level where this case study of violent failure occurred, as shown in previous figures of rock structure and stress. The interpreted sequence of rock mass reactions during the failure are discussed as follows and numbered chronologically in Figure 12.

1) The northern abutment fails under compression due to concentrated stress and low confinement to the southeast due to the cave. A dislocation surface likely opened along a member of Fault Set \#1, with the rock mass precinct east of this structure being displaced to the southeast. No excavation damage can be directly attributed to this process, despite workings coincident with the source of seismicity.

2) Load is transferred from the failing northern abutment to adjacent areas. Felsic boundaries and Fault Set \#2 structures in the west domain are heavily loaded as a result, causing local sites of energy release on these features. Ground support damage occurs where features intersect mine excavations.

3) Major Structure \#1 is heavily loaded due to the reactions of adjacent felsic rock types and structures in the west domain. Rapid accumulation of shear strain energy occurs on this structure as a result, causing highly localised ruptures where intersecting mine excavations.

4) Further loading reactions occur along the felsic boundary to the south of Major Structure \#1, but only minor damage was observed. 


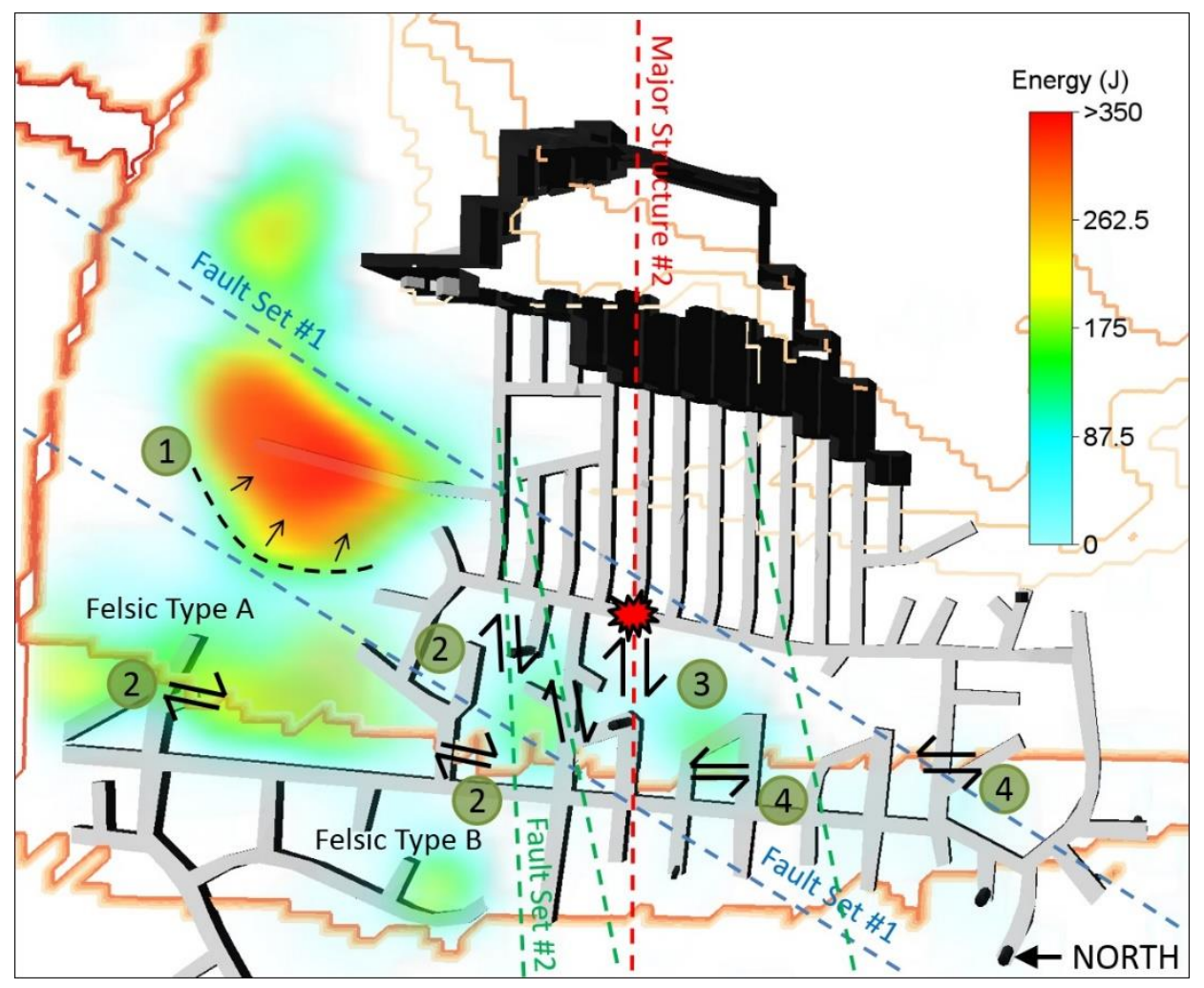

Figure 12 - Failure mechanism sketch showing radiated seismic energy (inferred rock mass damage) and interpreted structural reactions.

The damage to ground support on this level is illustrated in Figure 13 which presents the failure source analysis results and point dataset of seismic events for direct comparison to this damage. Damage severity is represented graphically according to the scale described below in Table 2.

This analysis indicates that severe ground support damage did not coincide with the most energetic seismic activity. In fact, damage was most intense throughout the central region of the west domain where major structural features were present and the mining induced stress conditions prior to failure were predicted to be relatively low in the order of $40 \mathrm{MPa}$. On the basis of these observations, it is interpreted that excavation damage was the result of broad scale, structurally controlled mechanisms of load transfer. Variable dynamic loads were generated throughout the mine as a result of these discrete structural reactions. Stress-driven strain bursting may have played a role in some of the less severe damage locations. Due to the absence of any excavation damage at the hypocentre of most intense seismic activity, dynamic stress waves are not believed to be significant factors influencing the occurrence of damage. The absence of any damage in this area suggests that medium energy dissipation capacity ground support schemes have a high tolerance to loading by dynamic stress waves. 


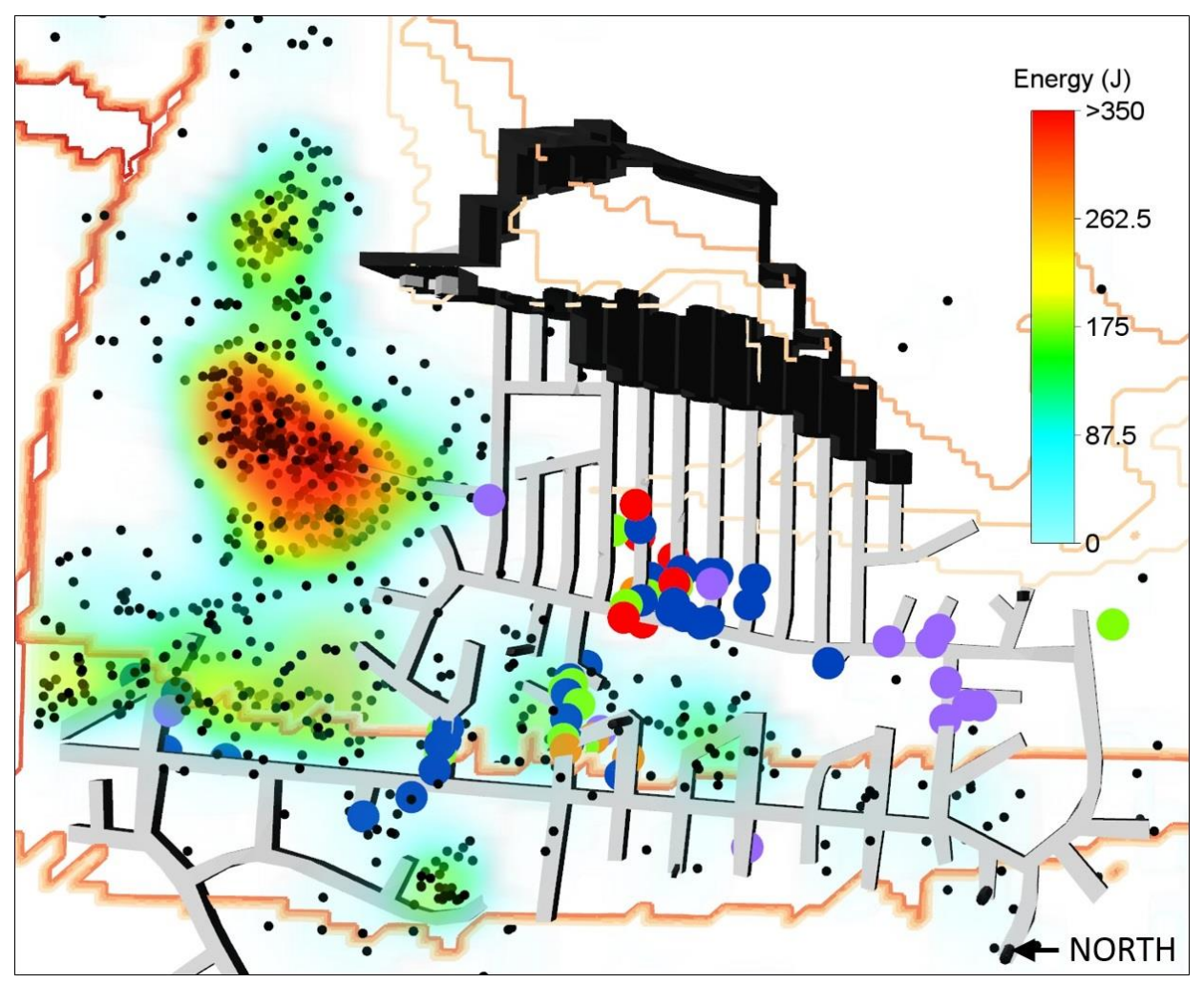

Figure 13 - Overlay of contours of radiated seismic energy, recorded seismic events and ground support damage locations.

Table 2 - Reinforcement and surface support damage scale.

\begin{tabular}{|c|l|l|}
\hline Damage & \multicolumn{1}{|c|}{ Reinforcement damage } & \multicolumn{1}{c|}{ Surface Support Damage } \\
\hline Minimal & No new damage or loading. & $\begin{array}{l}\text { Cracking in fibrecrete is very fine or widely } \\
\text { distributed. }\end{array}$ \\
\hline Low & $\begin{array}{l}\text { Minor loading and deformations of } \\
\text { reinforcement surface fixtures. }\end{array}$ & $\begin{array}{l}\text { Fibrecrete cracking and possibly small } \\
\text { blocks dislodged, minor mesh bagging. } \\
\text { Retention function still effective. }\end{array}$ \\
\hline Moderate & $\begin{array}{l}\text { Significant loading and deformation of } \\
\text { reinforcement surface fixtures, causing } \\
\text { some failures. Isolated loss of } \\
\text { reinforcement function. }\end{array}$ & $\begin{array}{l}\text { Fibrecrete fractured and small blocks de- } \\
\text { bonded from rock, moderate bagging of } \\
\text { mesh with some strand failures and } \\
\text { separation of the overlap. Isolated loss of } \\
\text { retention. }\end{array}$ \\
\hline High & $\begin{array}{l}\text { Many broken rock bolts and heavy } \\
\text { loading of remaining fixtures. Rock } \\
\text { ejection and loss of reinforcement } \\
\text { function between components. }\end{array}$ & $\begin{array}{l}\text { Fibrecrete deeply fractured and unstable, } \\
\text { mesh often torn and pulled over bolt plates, } \\
\text { rock ejection at overlap and where torn. } \\
\text { Frequent loss of retention. }\end{array}$ \\
\hline Severe & $\begin{array}{l}\text { Most rock bolts broken and rock } \\
\text { unravelled around bolts. Complete } \\
\text { failure of reinforcement function. }\end{array}$ & $\begin{array}{l}\text { Fibrecrete, mesh and rock ejected, mesh } \\
\text { heavily torn and damaged. Complete loss of } \\
\text { retention. }\end{array}$ \\
\hline
\end{tabular}




\section{Excavation Damage and Loading Conditions}

The focus of this case study is a particularly violent failure in the west access drive of a production level located at a depth of 1055 metres below surface. In this case the failure resulted in ejection of one of the walls of the excavation. The energy was such that the surface support system was ejected, coming to rest partially intact and upright against the opposite wall. A mass of rock estimated at 140 tonnes was also displaced. Figure 14 depicts two views of the failure: a) from the south looking north and b) a close up of the ejected block of surface support and embedded rock against the opposite wall. This level of damage is indicative of an extremely high energy demand and ejection velocity. Figure 15a) provides a reverse angle view of the ejected surface support while $15 \mathrm{~b}$ ) shows a photograph of a nearby location subject to moderate loading demands. Figure 15b illustrates a similar but much lower energy mechanism of surface support loading between the spacing of the reinforcement elements.
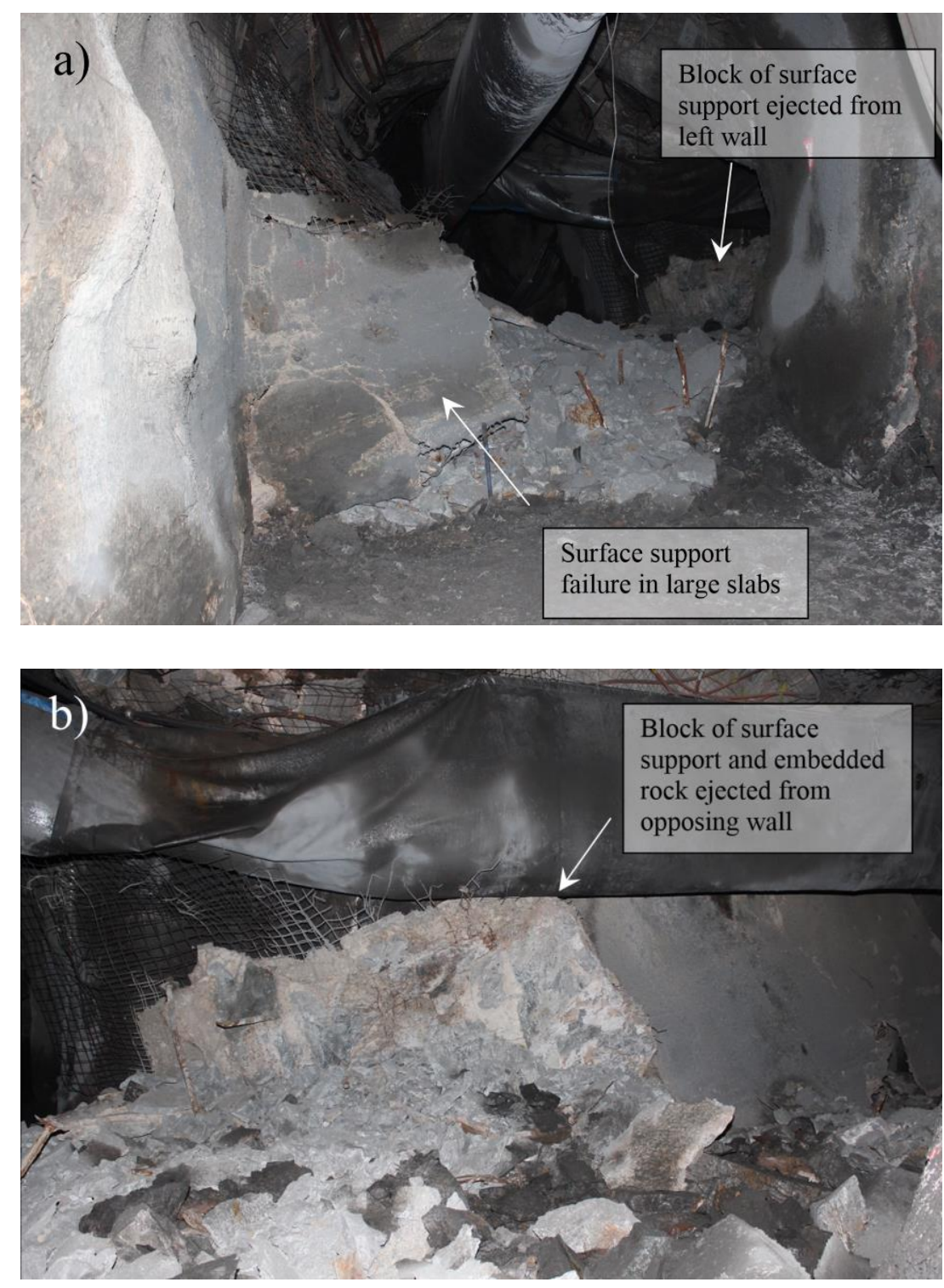

Figure 14 - Failure of ground support scheme leading to violent, very high velocity ejection. 

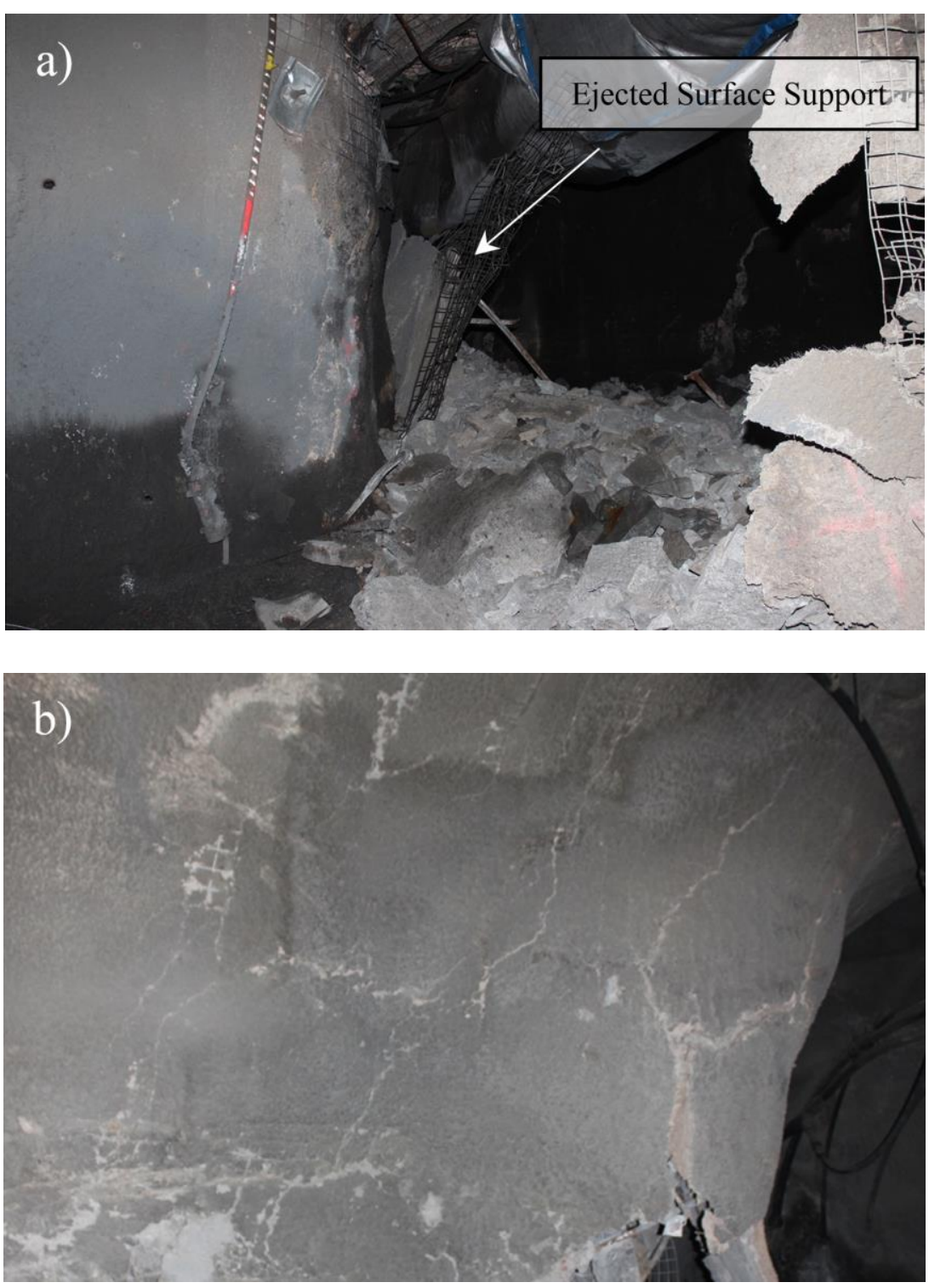

Figure 15 - a) Surface support damage after extremely high loading demand, b) surface support damage after low to moderate loading demand. Fracture pattern reflects reinforcement spacing with bolt locations where cracks intersect.

The mechanism of wall ejection is interpreted as a structurally controlled release of strain energy associated with highly localised rupture of the fault surface. Significant shear displacements along Major Structure \#1 which would cause comparable damage to the adjacent roof and opposite wall near the failure were not observed. Such damage would be expected for a large scale fault rupture. The absence of such damage implies that the cause of the failure was a highly localised condition where the induced shear stresses acting on the structure exceeded the shear strength. This may be a function of the joint conditions on the structure at the failure location and the influence of the excavation on local structure confinement. 


\section{Dynamic Demand Estimates}

The field observations of ground support performance following this failure provide a unique opportunity to conduct estimates of loading demands using back analysis techniques. The wall ejection has been analysed in this case using simple projectile motion equations. In this analysis the large block of surface support ejected across the excavation as shown in Figure 14b has been treated as a projectile. Estimates of the ejection velocity have been made based on accurately measured displacements. The equations of motion used for this analysis are as follows:

$$
\begin{aligned}
& x=V_{i x} t+0.5 a_{x} t^{2} \\
& y=V_{i y} t+0.5 a_{y} t^{2}
\end{aligned}
$$

Where $x$ = final horizontal displacement, $y=$ final vertical displacement, $V_{i x}=$ initial horizontal ejection velocity, $V_{i y}=$ initial vertical ejection velocity, $a_{x}=$ horizontal acceleration, $a_{y}=$ vertical acceleration, $t$ $=$ time.

The final displacements in both the horizontal and vertical plane have been measured using high definition 3D survey data captured using a precision laser device. A reference origin and endpoint of ejection were established for this purpose by tracing visible damage in the ejected material back to the original excavation surface. Mesh failure at the face plate was traced back to a specific rock bolt location as shown in Figure 16. The measured displacements between these points were used as the equation inputs, as shown in Figure 17, which presents a view of the survey data looking north along the orientation of the excavation and perpendicular to the projectile path of the ejected surface support.

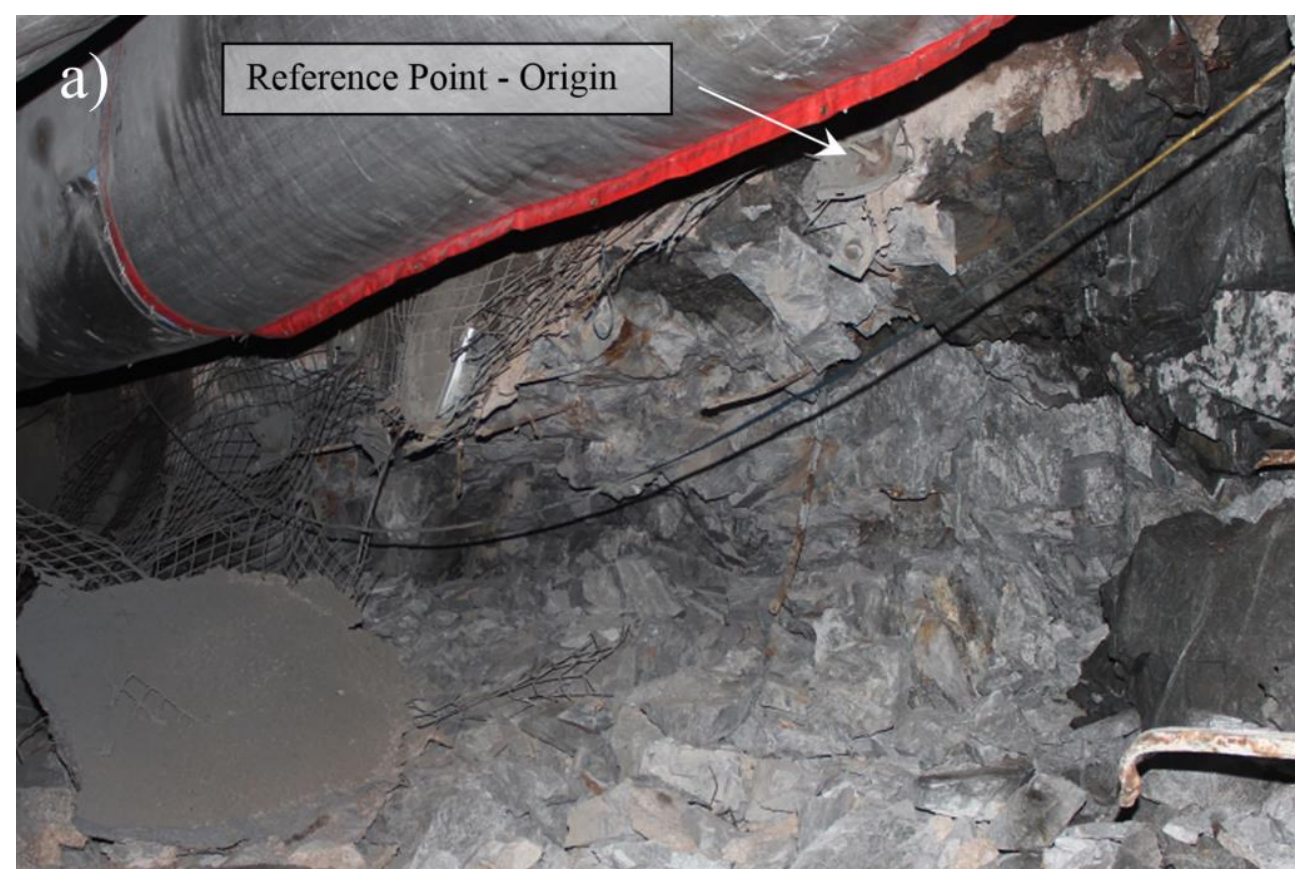




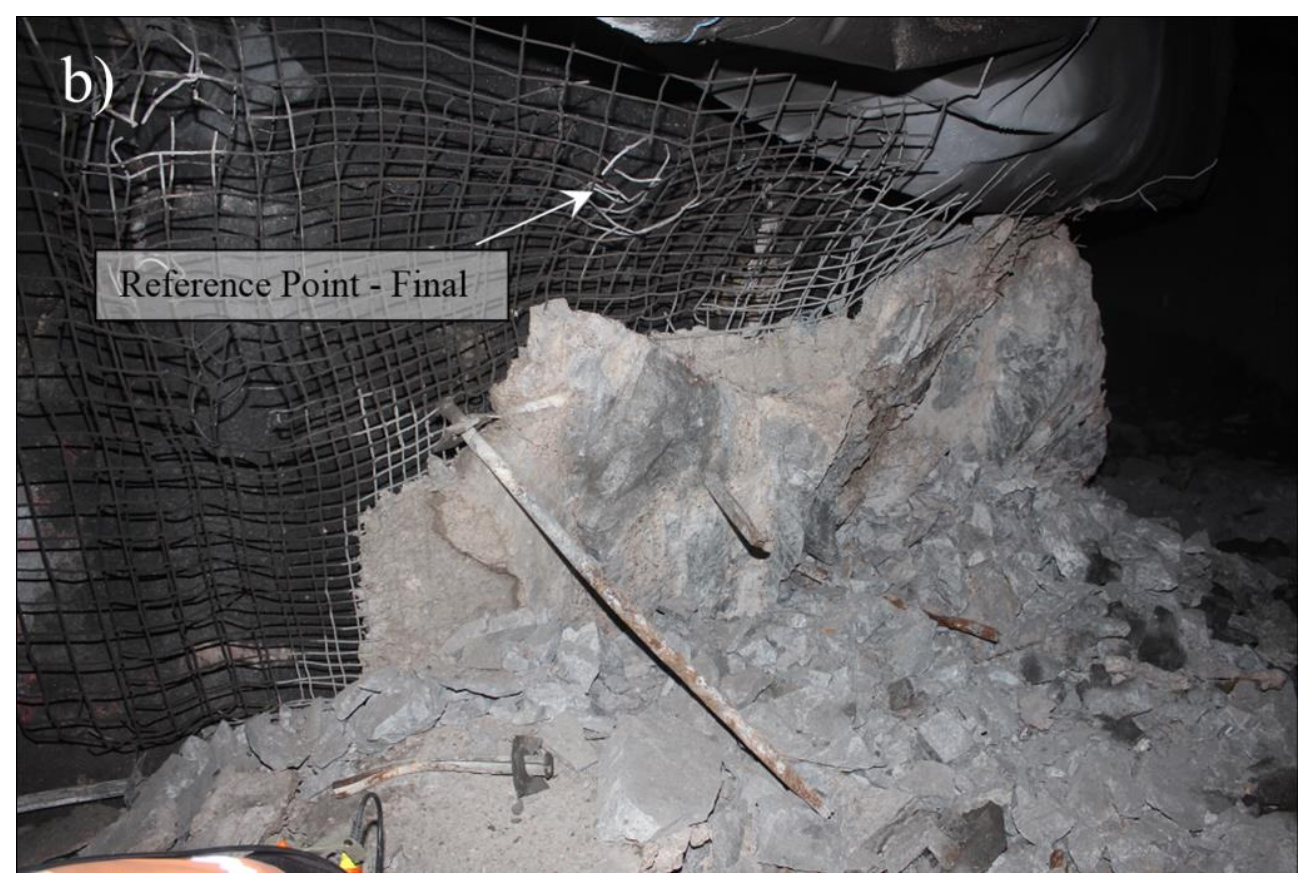

Figure 16 - a) Origin point of zero displacement and b) final reference point for projectile equations.

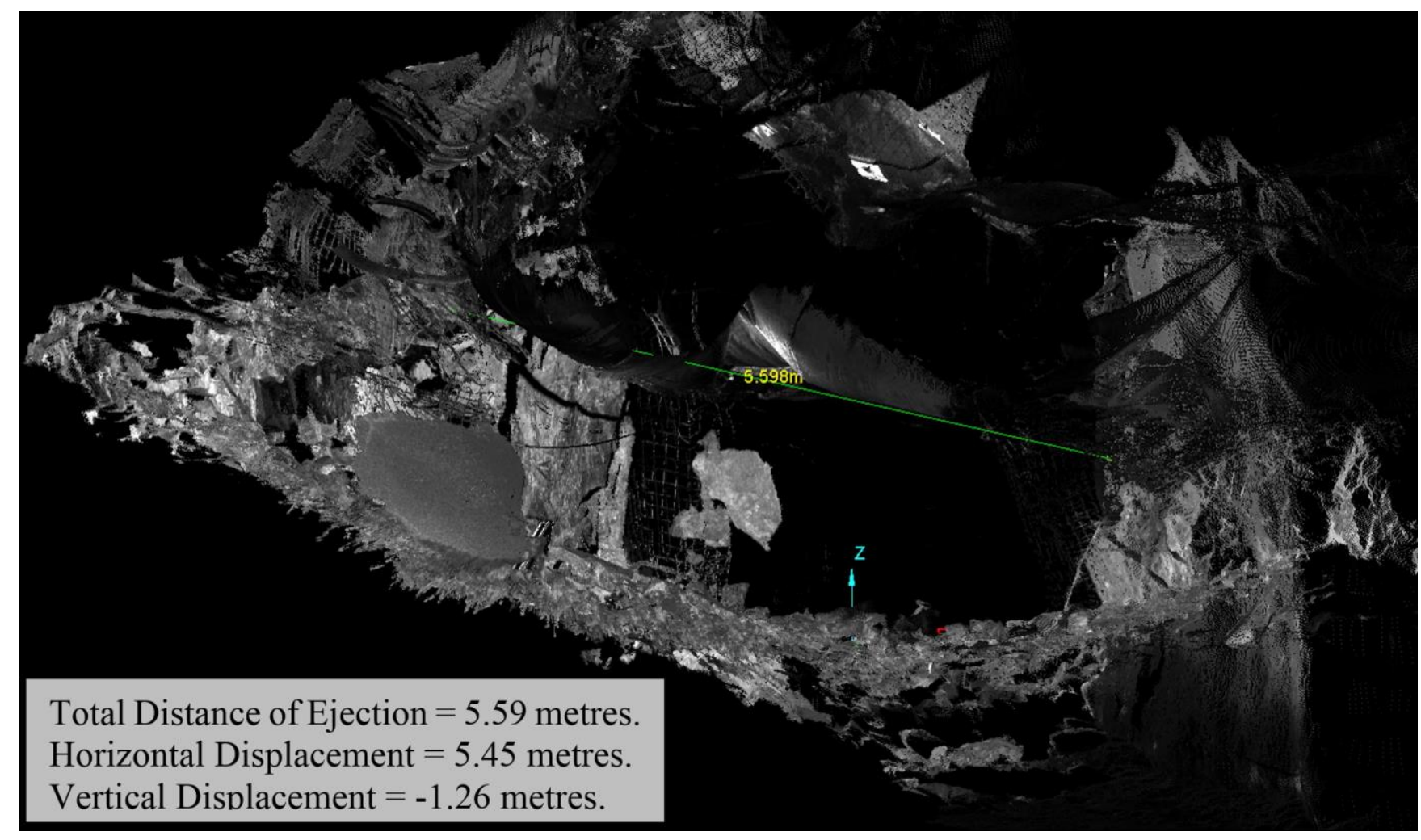

Figure 17 - Dimensions of the ejection path of the large block of support/rock, taken from HD survey scan data, view direction north, as in (Figure 14a). 
Rearranging equation (3) and solving for the flight time of the ejected block and using $y=-1.264 \mathrm{~m}, a_{y}$ $=\mathrm{g}=9.81 \mathrm{~m} / \mathrm{s}$ and $V_{i y}=0 \mathrm{~m} / \mathrm{s}$, the time, $\mathrm{t}$, can be calculated as follows;

$$
\begin{aligned}
t & =\sqrt{\frac{2 y}{a_{y}}} \\
& =\sqrt{\frac{2(1.264)}{9.81}} \\
& =0.51 \text { seconds }
\end{aligned}
$$

Now, rearranging Equation (2) to solve for the ejection velocity of failed surface support using $x=$ $5.453 \mathrm{~m}$ and $a_{x}=0 \mathrm{~m} / \mathrm{s}^{2}$, the ejection velocity, $V_{i x}$, can be calculated as follows;

$$
\begin{aligned}
V_{i x} & =\frac{x}{t} \\
& =\frac{5.453}{0.51} \\
& =10.7 \mathrm{~m} / \mathrm{s}
\end{aligned}
$$

This analysis makes several assumptions, including that the ejected material had no vertical component of initial velocity. It is also assumes that the final vertical position of the ejected block against the opposite wall coincides with the position at which the block struck the wall. One alternative possibility exists, being that the block struck the wall higher than its final resting position. This would require a higher ejection velocity than that calculated above, but this cannot be quantified.

This value of $10.7 \mathrm{~m} / \mathrm{s}$ is believed to be a realistic estimate of the ejection velocity of the failed surface support system. This result is comparable to the upper range of plausible ejection velocities for sudden violent excavation failures at great depth and stress (Ortlepp, 1992). The theoretical peak particle velocity (PPV) predicted at the site of failure due to the dynamic stress wave effects of remote large seismic events is calculated to be less than $1 \mathrm{~m} / \mathrm{s}$. This low value significantly underestimates the true ground motion and is incompatible with the severity of observed excavation damage, indicating that PPV is not applicable as a measure of ground support demand for such structurally controlled violent failures.

Given that the ejection velocity of the surface support has been estimated at $10.7 \mathrm{~m} / \mathrm{s}$, it is possible to draw some quantitative conclusions regarding the energy demand on the ground support scheme during failure. Several assumptions must be made concerning the dimensions of the loading mass of rock and transfer of kinetic energy between the rock and ground support scheme. The assumption regarding the loading mass is related to the measured depth of failure. The maximum depth of failure was measured to be 3.0 metres. This dimension is shown below in Figure 18 which presents high definition survey data of the damage in a view perpendicular to the wall of the excavation and direction of rock mass ejection.

No apparent deformation of the wall support was observed at the site prior to the failure, indicating that very little pre-existing stress driven broken ground and rock bulking occurred in the excavation wall prior 
to the violent failure. Furthermore, such a sudden and violent failure mechanism would be highly unlikely to occur if the rock mass was heavily fractured and unable to sustain significant load. As such, the survey data is believed to represent the depth of failure generated in the instant of the dynamic event, not as a result of time-dependent, stress driven rock fracturing. Nonetheless, the volume of this ejected rock mass which directly loaded the ground support scheme is subject to uncertainty.

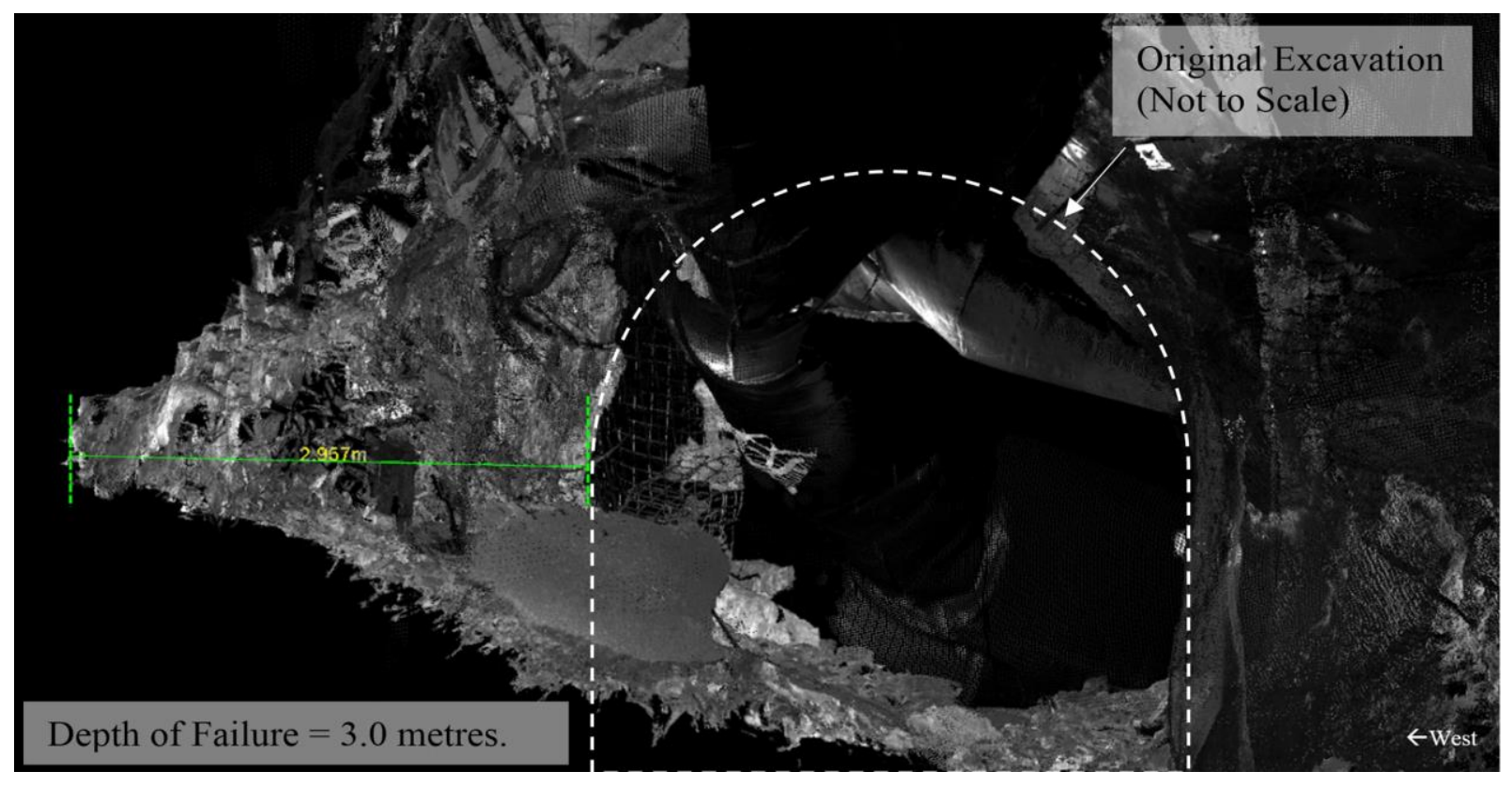

Figure 18 - Maximum depth of rock mass failure of 3.0m caused by sudden violent event.

The transfer of kinetic energy between the rock and ground support scheme is complex. The structural characteristics of the rock mass such as jointing and foliation heavily influence the dynamic fracturing process. The loading mass depends on where these planes of weakness are located with respect to the reinforcement embedment depth. It is plausible that the loading mass acting on the reinforcement is different to that acting on the surface support due to the rapid sequence of fracture generation as the depth of rock mass failure propagates. As such, it is difficult to define a common loading mass via back analysis.

The mass of rock loading the surface support scheme components depends on where dynamic fracturing was initiated, the sequence of fracture creation/dilation and the depth to which rock ejection propagated before causing the components to fail. In this case study it is likely that the energy dissipation capacity of the support scheme was fully consumed prior to the rock mass failure propagating to its full depth. Therefore, only a portion of the ejected rock mass directly loaded the surface support.

Taking into account the final depth of failure and observed retention deficiencies of the reinforcement elements due to poor resin encapsulation at the collar, as shown in Figure 19, it is considered reasonable and conservative to assume that only the first metre of ejected rock directly loaded the surface support. This assumes that the surface support failed and fragments were ejected in the instant that the rock mass failure propagated beyond one metre in depth. The loading mass per square metre would be a cubic metre of felsic rock with unit weight $2700 \mathrm{~kg} / \mathrm{m}^{3}$. 


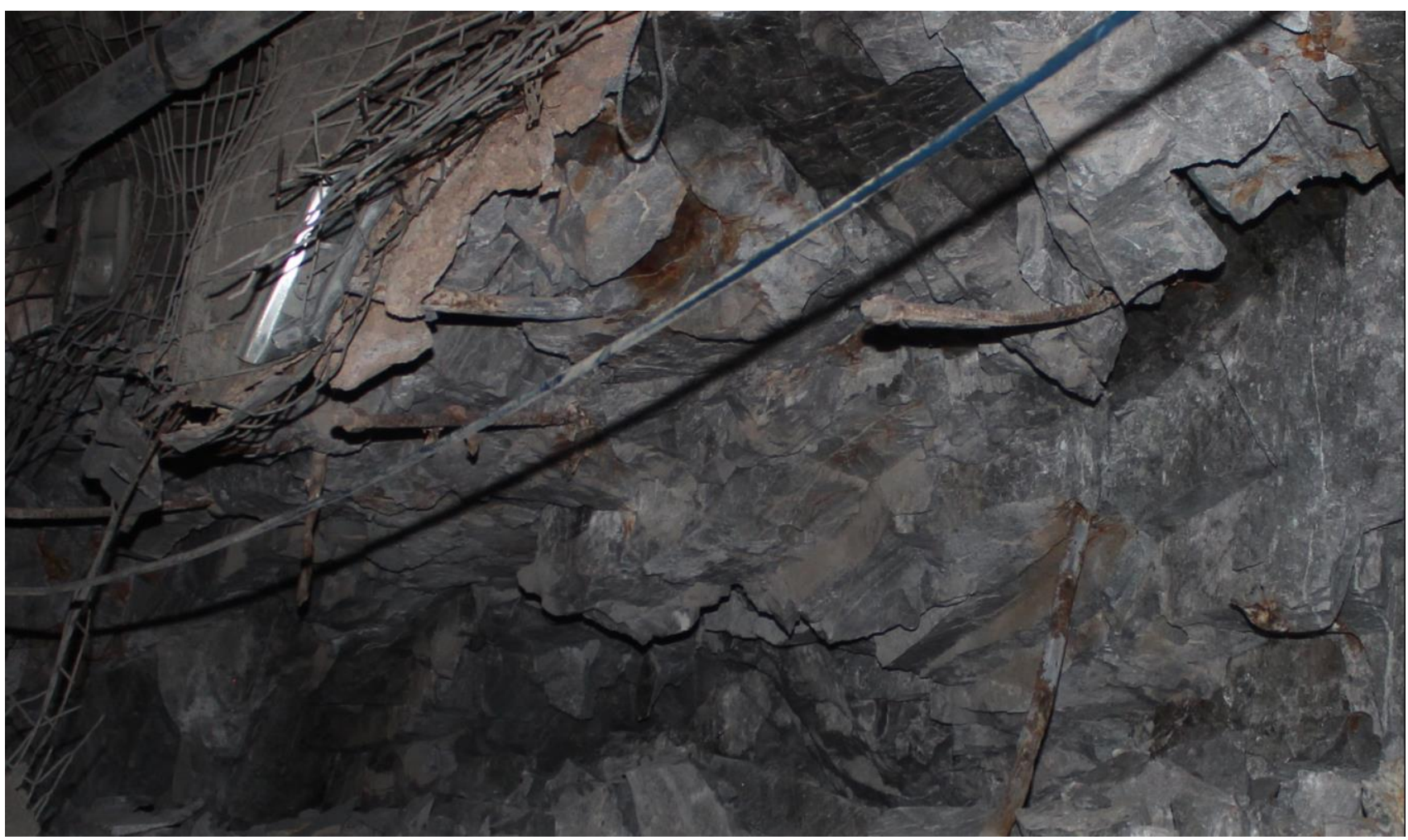

Figure 19 - Reinforcement retention inconsistency due to poor resin encapsulation at the collar likely caused the first metre of rock mass instability to preferentially load the surface support.

A final assumption used in this analysis is that the transfer of momentum between the loading mass of rock and ejected support fragments is such that the velocity of the rock mass and post-failure ejection velocity of the surface support is equivalent at $10.7 \mathrm{~m} / \mathrm{s}$. Carrying these assumptions, an estimate of the dynamic energy demand imposed on the surface support scheme per square metre of area is as follows.

$$
\begin{aligned}
\text { Demand } & =\frac{1}{2} m v^{2} \\
& =\frac{1}{2}(2700)\left(10.7^{2}\right) \\
& =154.5 \mathrm{~kJ}
\end{aligned}
$$

The energy dissipation capacity of the installed ground support was approximately $10.5-18 \mathrm{~kJ} / \mathrm{m}^{2}$, as per the design capacity described earlier. Therefore, an energy surplus of around $136 \mathrm{~kJ} / \mathrm{m}^{2}$ was available to cause violent ejection of support fragments and ongoing projectile motion of the rock mass. Although several simplifying assumptions have been made in this analysis, this demand estimate is considered to be conservative. When considering this demand estimate it is imperative to place it in context. The demand is highly localised to an area of only several square metres where extremely high strain energy has been release due to local rupture along structure. This process occurred in a fraction of a second under intense loading conditions. 
These observations suggest that high energy, structurally controlled failure mechanisms cannot be reliably managed using common excavation design and construction techniques. More robust methods of excavation design, construction and monitoring are required in order to ensure mining operations can continue safely in such conditions. These factors are currently the subject of an industry sponsored project run by the Western Australian School of Mines, Curtin University, CRC Mining.

\section{Conclusions}

This case study has examined a large structurally controlled failure event occurring in a deep hardrock underground mine at a depth of 1055 metres below surface. The back analysis of this failure concludes that the failed surface support system was ejected from the wall of the excavation with an initial velocity of $10.7 \mathrm{~m} / \mathrm{s}$. Estimates of the mechanical demand imparted to the ground support scheme during failure were also performed. These estimates carry several assumptions in order to simplify complex uncertainties concerning the dimensions of the loading mass of rock and transfer of kinetic energy between the rock and ground support scheme. However, the demand on surface support may be conservatively assumed to be at least $150 \mathrm{~kJ} / \mathrm{m}^{2}$. This demand was isolated to an area of several square metres where the excavation violently failed due to a structurally controlled loading mechanism occurring during a period of mine-scale rock mass instability. The conditions at this mine may be representative of the excavation loading demands experienced by an increasing number of mines in the future as near-surface mineral resources are depleted and deeper deposits are explored.

\section{References}

Brown, E. T., 1981. Rock Characterisation, Testing and Monitoring - ISRM Suggested Methods. Oxford, U.K.: Pergamon.

Duplancic, P., 2001. Characterisation of caving mechanisms through analysis of stress and seismicity. $\mathrm{PhD}$ Thesis, University of Western Australia.

Eneva, M., Van Aswegen, G. \& Mendecki, A., 1998. Volume of ground motion and seismic hazard. International Journal of Rock Mechanics and Mining Sciences.

Levkovitch, V., Beck, D. \& Reusch, F., 2013. Numerical simulation of the released energy in strainsoftening rock materials and its application in estimating seismic hazard in mines. 8th International Symposium on Rockbursts and Seismicity in Mines.

Ortlepp, W., 1992. Impulsive load testing of tunnel support. Edited by P Kaiser and D McCreath, Rock Support in Mining and Underground Construction, Proceedings of the International Symposium on Rock Support, pp. 675-682.

Villaescusa, E., Player, J. \& Thompson, A., 2014. A reinforcement design methodology for highly stressed rock masses. 8th Asian Rock Mechanics Symposium.

Windsor, C., 2008. Reconciliation of Strain, Structure, Strength \& Stress. Confidential Project Report, Western Australian School of Mines. 